WSRC-TR-99-00434, Rev. 0

\title{
CIM5 Phase III Base Process Development Results
}

by

D. C. Witt

Westinghouse Savannah River Company

Savannah River Site

Aiken, South Carolina 29808

T. M. Jones

DOE Contract No. DE-AC09-96SR18500

This paper was prepared in connection with work done under the above contract number with the U. S.

Department of Energy. By acceptance of this paper, the publisher and/or recipient acknowledges the U. S. Government's right to retain a nonexclusive, royalty-free license in and to any copyright covering this paper, along with the right to reproduce and to authorize others to reproduce all or part of the copyrighted paper. 
WESTINGHOUSE SAVNNAH RIVER COMPANY

WSRC-TR-99-0434TL SAVANNAH RIVER TECHNOLOGY CENTER

Date: $12 / 1 / 99$

TO: W. H. MARTIN, 730-2B

FROM: L. F. LANDg

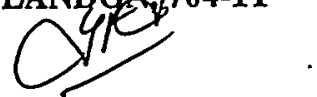

. CIM5 PHASE III BASE PROCESS DEVELOPMENT RESULTS

The attached document summarizes the results of the base process development tests conducted in the $\mathrm{Am} / \mathrm{Cm}$ Pilot Facility located in Building 672-T. Please refer any questions you may have regarding the contents of this document to D. C. Witt (Ext. 7-7754) or T. M. Jones (Ext. 7-7706).

\section{DISTRIBUTION}

J. T. Dahlstrom, 730-1B

A. W. Bowers, 704-10F

A. P. Giordano, 730-1B

A. P. Fellinger, 730-1B

N. H. Harkey, 730-1B

D. C. Witt, 704-1T

T. M. Jones, 704-1T

STI 703-43A (4) 
WSRC-TR-99-00434, Revision 0

\section{CIM5 PHASE III BASE PROCESS DEVELOPMENT RESULTS (U)}

D. C. Witt

T. M. Jones

Westinghouse Savannah River Company

Savannah River Site

Aiken, SC 29808

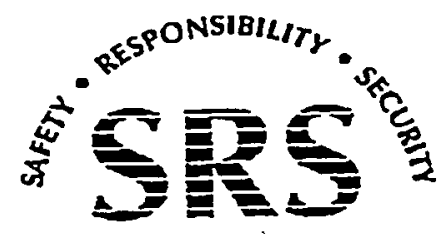

PREPARED FOR THE U.S. DEPARTMENT OF ENERGY UNDER CONTRACT NO. DE-AC09-96SR18500 


\section{DISCLAIMER}

This report was prepared as an account of work sponsored by an agency of the United States Government. Neither the United States Government nor any agency thereof, nor any of their employees, makes any warranty, express or implied, or assumes any legal liability or responsibility for the accuracy, completeness, or usefulness of any information, apparatus, product or process disclosed, or represents that its use would not infringe privately owned rights. Reference herein to any specific commercial product, process or service by trade name, trademark, manufacturer, or otherwise does not necessarily constitute or imply its endorsement, recommendation, or favoring by the United States Government or any agency thereof. The views and opinions of authors expressed herein do not necessarily state or reflect those of the United States Government or any agency thereof.

This report has been reproduced directly from the best available copy.

Available for sale to the public, in paper, from: U.S. Department of Commerce, National Technical Information Service, 5285 Port Royal Road, Springfield, VA 22161, phone: (800) 553-6847

fax: (703) 605-6900

email: orders@ntis.fedworld.gov

online ordering: http://www.ntis.gov/ordering.htm

Available electronically at http://www.doe.gov/bridge

Available for a processing fee to U.S. Department of Energy and its contractors, in paper, from: U.S. Department of Energy, Office of Scientific and Technical Information, P.O. Box 62, Oak Ridge, TN 37831-0062, phone: (865) 576-8401

fax: (865) 576-5728

email: reports@adonis.osti.gov 


\section{DISCLAIMER}

Portions of this document may be illegible in electronic image products. Images are produced from the best available original document. 
WSRC-TR-99-00434, Revision 0

Keywords: Am/Cm, CIM5,

Preferred process

Retention: Permanent

\section{CIM5 PHASE III BASE PROCESS DEVELOPMENT RESULTS (U)}

D. C. Witt

T. M. Jones

Publication Date: November 24, 1999

Westinghouse Savannah River Company

Savannah River Site

Aiken, SC 29808

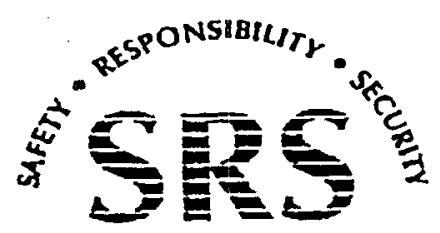

SAVANNAH RIVER SITE

PREPARED FOR THE U.S. DEPARTMENT OF ENERGY UNDER CONTRACT NO. DE-AC09-96SR18500 
APPROVALS

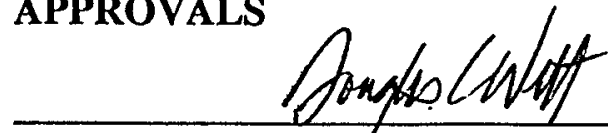

D. C. Witt, Author

$\frac{\text { Remitting mon es }}{\text { T. M: Jones, Author }}$

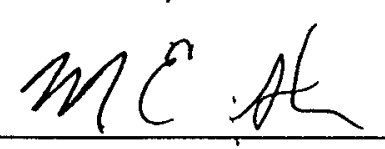

M. E. Stone, Technical Reviewer

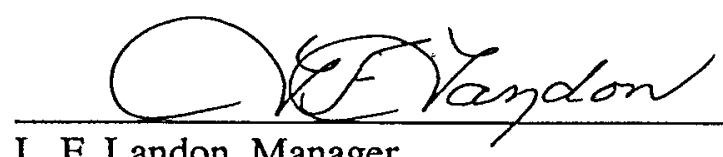

L. F. Landon, Manager $\frac{11 / 24 / 99}{\text { Date }}$

$\frac{11 / 24 / 99}{\text { Date }}$

$\frac{11 / 29 / 99}{\text { Date }}$

$\frac{11 / 29 / 99}{\text { Date }}$ 
TABLE OF CONTENTS

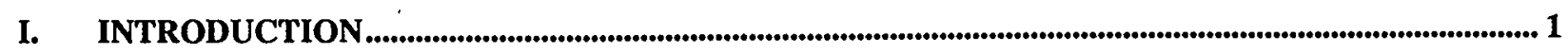

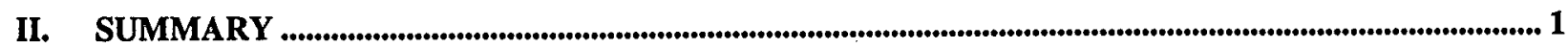

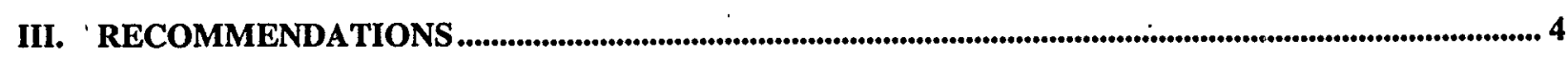

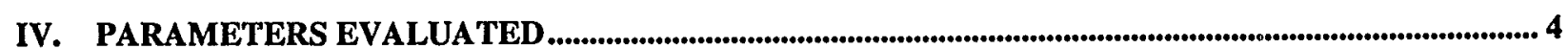

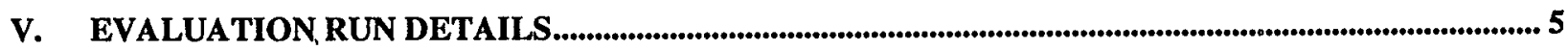

V.A. EVALUATION OF PROCESSING EXTREMES WITH 58 WT\% LN 25SRABS GLASS BATCH ............................. 5

V.B. EVALUATION OF LOWER LANTHANIDE LOADINGS TO MITIGATE DRAIN TUBE PLUGGING .......................... 18

V.C. BUBBLER EVALUATION TO HOMOGENIZE 49 WT\% LN LOADED 25SRABS GLASS ................................... 28

V.D. EVAluation OF PROCESS EXTREME CONDITIONS WITH AM/CM BASE PROCESS - 49 WT\% LN 25SRABS

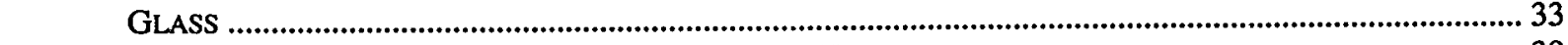

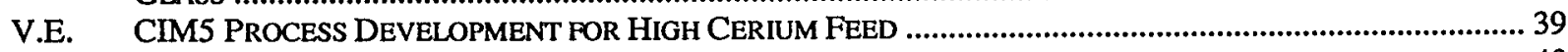

V.F. EVALUATION OF AM/CM BASE PROCESS EXTREME CONDITIONS.............................................................. 40

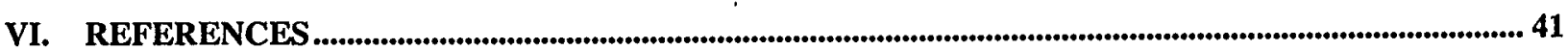

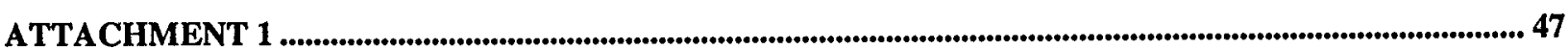

CIMS PHASE III PROCESS DEVELOPMENT HIGHLIGHTS ..................................................................................... 47

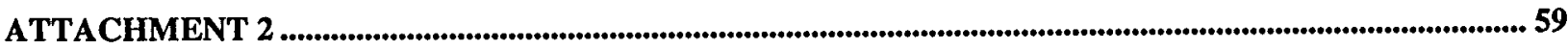

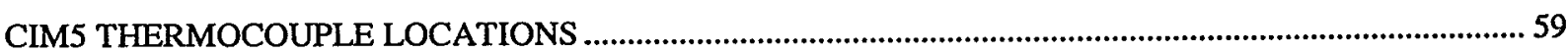


This page intentionally left blank. 
WSRC-TR-99-0434

Page 1 of 59

\section{INTRODUCTION}

Integrated Demonstration Runs for the $\mathrm{Am} / \mathrm{Cm}$ vitrification process were initiated in the Coupled 5" Cylindrical Induction Melter (CIM5) on 11/30/98 and completed on 12/9/98. Four successful runs at $60 \mathrm{wt} \%$ lanthanide loading were completed which met or exceeded all established criteria. The operating parameters used in these runs established the base conditions for the 5" Cylindrical Induction Melter (CIM5) process and were summarized in the 5" CIM design basis, SRT-AMC-99-0001 ${ }^{1}$.

In subsequent tests, a total of fourteen CIM5 runs were performed using various power inputs, ramp rates and target temperatures to define the preferred processing conditions ${ }^{2}$. Process stability and process flexibility were the key criteria used in assessing the results for each run. A preferred set of operating parameters was defined for the CIM5 batch process and these conditions were used to generate a pre-programmed, automatic processing cycle that was used for the last six CIM5 runs ${ }^{3}$. These operational tests were successfully completed in the January-February time frame and were summarized in SRT-AMC-99-0058 ${ }^{4}$.

The recommended set of operating conditions defined in Runs \#1 through \#14 was used as the starting point for further pilot system runs to determine the robustness of the process, evaluate a bubbler, and investigate off-normal conditions. CIM5 Phase III Runs $\# 15$ through \#60 were conducted utilizing the pre-programmed, automatic processing cycle to investigate system performance. This report summarizes the results of these tests and provides a recommendation for the base process as well as a processing modification for minimizing volume expansions if americium and/or curium are subject to a thermal reduction reaction like cerium.

\section{SUMMARY}

Base process development tests in the CIM5 were successfully completed. A total of 45 CIM5 runs were performed investigating potential off-normal conditions. Vitrification runs were performed to define processing conditions that would produce an acceptable glass product under each of the potential off-normal conditions evaluated.

The CIM5 base process consisting of a preferred set of operating parameters and a preprogrammed, automatic processing cycle was established in the CIM5 operational tests ${ }^{4}$ (Runs \#1 - \#14) using a 58 wt\% lanthanide ( $L n)$ loaded 25SrABS glass. The preprogrammed, automatic processing cycle is shown in Table 1. The next step in the development program was to evaluate the $58 \mathrm{wt} \% \mathrm{Ln}$ base process over several processing extremes. The conditions chosen for evaluation were several increased cerium concentrations that would simulate the thermal reduction of americium and/or curium and the recovery from an interlock condition during the vitrification phase. At the $58 \mathrm{wt} \% \mathrm{Ln}$ loading no appreciable volume expansion was experienced at any of the cerium 
concentrations (1.5X, 2.0X, 1.7X and 1.87X the normal cerium concentration) evaluated. However, two drain tube plugs were encountered which were attributed to the high liquidus temperature of the $58 \mathrm{wt} \% \mathrm{Ln}$ loaded glass. Devitrification and resultant pluggage of the drain tube presents a serious processing problem and, therefore, subsequent runs were aimed at evaluating lower Ln loadings to prevent drain tube pluggage.

Table 1. CIM5 Standard Power Application Sequence

\begin{tabular}{|c|c|c|c|c|c|c|}
\hline $\begin{array}{l}\text { RUN } \\
\text { TIME } \\
\text { (Minutes) }\end{array}$ & $\begin{array}{l}\text { Vessel } \\
\text { Coil } \\
\text { Power } \\
\text { (kw) }\end{array}$ & $\begin{array}{l}\text { Vessel } \\
\text { Power } \\
\text { Ramp } \\
\text { (kw/min) }\end{array}$ & $\begin{array}{l}\text { Vessel } \\
\text { Bottom } \\
\text { Power } \\
\text { (kw) }\end{array}$ & $\begin{array}{l}\text { Vessel } \\
\text { Bottom } \\
\text { Power } \\
\text { Ramp } \\
\text { (kw/min) }\end{array}$ & $\begin{array}{l}\text { Drain } \\
\text { Tube } \\
\text { Power } \\
\text { (kw) }\end{array}$ & $\begin{array}{l}\text { Drain } \\
\text { Tube } \\
\text { Power } \\
\text { Ramp } \\
\text { (kw/min) }\end{array}$ \\
\hline 1 & 1.30 & $\begin{array}{c}1.30 . \\
*\end{array}$ & 0 & & 0 & \\
\hline 96 & 1.30 & & 0.43 & $\begin{array}{c}0.43 \\
*\end{array}$ & 0 & \\
\hline 136 & 1.30 & .018 & 0.43 & & 0.13 & $0.13 . *$ \\
\hline 156 & 1.66 & .0113 & 0.43 & & 0.13 & \\
\hline 171 & 1.83 & .0153 & 0.43 & & 0.13 & \\
\hline 186 & 2.06 & .0328 & 0.43 & & 0.13 & \\
\hline 221 & 3.21 & & 0.54 & $.09 . *$ & 0.13 & \\
\hline 236 & 3.21 & & 0.54 & .018 & 0.13 & \\
\hline 246 & 3.21 & & 0.72 & .010 & 0.13 & \\
\hline 251 & 3.21 & .022 & 0.77 & & 0.13 & \\
\hline 256 & 3.23 & .022 . & 0.77 & .020 & 0.26 & $\begin{array}{c}0.13 \\
*\end{array}$ \\
\hline 316 & 4.65 & .022 . & 1.96 & & 0.26 & \\
\hline 335 & 5.02 & & 1.96 & & 0.26 & .017 \\
\hline 350 & 5.02 & & 1.96 & & 0.52 & .033. \\
\hline 365 & 5.02 & & 1.96 & & 1.02 & \\
\hline
\end{tabular}

NOTE: * indicates a power input step change.

A potential solution to the plugging problem from the glass chemistry standpoint involved decreasing the target lanthanide $(\mathrm{Ln})$ loading. However, at the lower $\mathrm{Ln}$ loadings a rather large heel of high viscosity glass remained in the melter after a pour. To reduce the size of this glass heel a higher lanthanum (La) content cullet (e.g. 30SrABS or $35 \mathrm{SrABS}$ ) was also chosen for evaluation to increase the residual Ln content and, hence decrease the viscosity. Subsequent runs began investigating lower lanthanide loadings beginning with $50 \mathrm{wt} \% \mathrm{Ln}$ and progressing through 47, 52 and $55 \mathrm{wt} \%$ runs. All runs 
yielded favorable results. Glass pour initiation was reproducible, the pour rate profiles were consistent, and glass quality was good for each run. The 49 wt\% Ln loaded 25 SrABS glass was chosen as the preferred composition because it provided sufficient operating room to reduce the potential for devitrification while maintaining the desired viscosity at the target operating temperature.

Higher La content cullet (30SrABS and 35SrABS) was then evaluated with the best lanthanide loading candidate from the above series, the $49 \mathrm{wt} \% \mathrm{Ln}$ glass. The cullet for the 30SrABS and 35SrABS was produced from batch chemicals in the CIM5. Both the 30SrABS cullet and 35SrABS cullet resulted in significant volume expansions during processing. The lower softening temperature resulting from the additional lanthanum in the cullets interacted with the oxygen released from cerium reduction to increase the volume expansion severity.

A $49 \mathrm{wt} \%$ Ln loaded $25 \mathrm{SrABS}$ glass was selected as the preferred product, based upon the reduced potential for product devitrification, the behavior of the batch during the calcination and vitrification processes, and the pouring initiation behavior. There was no appreciable bed volume expansion during the vitrification processes of either the $47 \mathrm{wt} \%$, $50 \mathrm{wt} \%$ or $52 \mathrm{wt} \%$ Ln glass batches.

To reduce the compositional variation in the poured glass stream, five runs were conducted using argon bubbling during the final high temperature soak period to facilitate mixing within the glass pool. All five runs showed marked improvement in the homogenization of the final glass product as evidenced by the measured pour rates and the appearance of the pour samples collected. The purpose of these runs was to bracket the acceptable bubbler operating region. Bubbling for 60 minutes at $1.0 \mathrm{scfh}$ appeared to produce an acceptable, homogeneous glass. However, bubbling at $1.0 \mathrm{scfh}$ for 15 minutes was insufficient to homogenize the glass. Bubbling times of 30 and 45 minutes appeared to be marginal, based upon pour rate data and visual observation of the samples collected.

Based on the success of these five bubbler runs, the base process was changed to include the use of a bubbler in the production of a $49 \mathrm{wt} \% \mathrm{Ln}$ loaded $25 \mathrm{SrABS}$ glass. This method of operation was shown to produce a more homogeneous glass product that results in a more predictable and reproducible residual glass composition. The advantage is the reduced risk of a drain tube plug caused by exceeding the liquidus temperature of the highly loaded, unmixed glass in the bottom of the melter.

With the base process specified, the next step in the development program evaluated the 49 wt\% Ln base process over several processing extremes. The conditions chosen for evaluation were the recovery from an interlock condition during the vitrification phase and increased cerium concentrations that would simulate the potential thermal reduction of americium and/or curium. Recovery from the high temperature interlock went smoothly and presented no processing problems. However, increased cerium concentrations in the $49 \mathrm{wt} \% \mathrm{Ln}$ SrABS glass resulted in significant volume expansions that presented serious processing problems. 
WSRC-TR-99-0434

Page 4 of 59

A process was developed to mitigate these severe volume expansions in the event that americium and/or curium are thermally reduced. Initially a smaller cullet charge was added to the melter to produce a 58 itt $\%$ Ln loaded glass. The CIM5 base process was then used to dry, calcine and vitrify the glass. At the beginning of the normal soak period $\left(\sim 1400{ }^{\circ} \mathrm{C}\right)$ the bubbler was inserted and an additional amount of cullet was added to attain a $49 \mathrm{wt} \% \mathrm{Ln}$ loaded final glass. The bubbler time was extended to 90 minutes due to the large heat loss caused by the cullet addition and 'the drain tube was energized earlier than usual to provide extra heat: to reduce the glass viscosity and promote better mixing. Approximately 30 grams of $49 \mathrm{SrABS}$ cullet ( $49 \mathrm{wt} \%$ lanthanum) was added to the melter after pouring was terminated to seal the top of the drain tube and significantly reduce the risk of drain tube pluggage.

\section{RECOMMENDATIONS}

1. A $49 \mathrm{wt} \% \mathrm{Ln}$ loading is recommended as the preferred 25SrABS glass, based upon the reduced potential for product devitrification, the behavior of the batch during the calcination and vitrification processes, and the pouring initiation behavior.

2. The base process should include the use of a bubbler in the production of a $49 \mathrm{wt} \%$ Ln loaded 25SrABS glass. This method of operätion was shown to produce a more homogeneous glass product that resulted in a more predictable and reproducible residual glass composition. The advantage is the reduced risk of a drain tube pluggage.

3. A process was developed to mitigate severe volume expansions in the event that americium and/or curium are thermally reduced. Initially a smaller cullet charge should be added to the melter to produce a $58 \mathrm{wt} \%$ Ln loaded glass. At the beginning of the normal soak period the bubbler should be inserted and an additional amount of cullet added to attain a $49 \mathrm{wt} \% \mathrm{Ln}$ loaded final glass. The sparge time should be extended to 90 minutes to sufficiently hömogenize the melt.

4. Approximately 30 grams of $49 \mathrm{SrABS}$ cullet ( $49 \mathrm{wt} \%$ lanthanum and cerium free) should be added to the melter after pour termination to seal the top of the drain tube and significantly reduce the risk of drain tube pluggage. A glass containing cerium is not recommended because of the bubbles and resulting porosity generated from the thermal reduction of cerium.

\section{PARAMETERS EVALUATED}

The oxalate precipitation process used to produce the surrogate feed stream for the Phase III base process evaluation runs was identical to that used for the integrated demonstration runs. Base conditions established for the operation of the melter were followed to evaluate how those values afforded the best combination of process stability 
WSRC-TR-99-0434

Page 5 of 59

and flexibility when the extremes of the operating window were approached. Conditions evaluated included:

- Evaluation of Processing Extremes with 58 Wt\% Ln 25SrABS Glass Batch

- Evaluation of Lower Lanthanide Loadings To Mitigate Drain Tube Plugging

- Bubbler Evaluation To Homogenize Base 49 Wt\% Ln 25SrABS Glass

- Evaluation of Process Extreme Conditions with Am/Cm Base Process - 49 wt\% Ln 25SrABS Glass

- Development of Process Modifications to Mitigate Bed Volume Expansions from Higher Cerium

A series of forty-five runs were conducted to evaluate the above parameters. An outline of each run showing the parameter values is included in Attachment 1. Run Plans for these runs are listed as References 11 through 66.

\section{EVALUATION RUN DETAILS}

\section{V.A. Evaluation of Processing Extremes with $58 \mathrm{Wt} \%$ Ln 25SrABS Glass Batch}

The CIM5 base process consisting of a preferred set of operating parameters and a pre-programmed, automatic processing cycle was established in the CIM5 operational tests ${ }^{4}$ (Runs \#1 - \#14) using a 58 wt\% lanthanide (Ln) loaded 25SrABS glass. The next step in the development program was to evaluate the 58 wt\% Ln base process over several processing extremes. The conditions chosen for evaluation were several increased cerium concentrations that would simulate the potential thermal reduction of americium ( $\mathrm{Am}$ ) and/or curium $(\mathrm{Cm})$ and the recovery from an interlock condition during the vitrification phase. These test were completed in CIM5 Runs \#15 through \#25. At the $58 \mathrm{wt} \%$ Ln loading no appreciable volume expansion was experienced at any of the cerium concentrations (1.5X, 2.0X, 1.7X and 1.87X the normal cerium concentration). However, two drain two plugs were encountered and were attributed to the high liquidus temperature of the $58 \mathrm{wt} \% \mathrm{Ln}$ loaded glass. Devitrification and resultant pluggage of the drain tube presents a serious processing problem and, therefore, subsequent runs were aimed at evaluating lower Ln loadings to prevent drain tube pluggage. Details for Runs \#15 through \#25 together with the drain tube recovery operations are provided in the subsections that follow.

\section{V.A.1. CIM5 Run \#15 - 58 wt\% Lanthanide Loaded 25SrABS Glass With $1.5 \times$ Cerium}

In the 1120 to $1150^{\circ} \mathrm{C}$ range, cerium is thermally reduced liberating oxygen gas. Am, and perhaps $\mathrm{Cm}$, may also be thermally reduced. 
Therefore, to determine the process effects of this additional oxygen liberation, a $58 \mathrm{wt} \%$ lanthanide $(\mathrm{Ln})$ glass that contained. $1.5 \mathrm{X}$ the standard amount of cerium (replaced an equivalent quantity of neodymium) was prepared. Routine processing was observed using the automatic power control program. No bed volume expansion was experienced. Previous runs in the 3"CIM had resulted in uncontrolled bed volume expansions above $1300^{\circ} \mathrm{C}$ when the cerium content in the precipitate feed was increased.

The cold glass plug dropped from the drain tube 44 seconds after the tip cooling air was shut off, followed by a steady stream of glass. Pour rate samples were collected continuously for 9 seconds each during the pour to establish a lanthanide concentration profile for the drain tube and melter volume. The measured pour rates and $\mathrm{Ln}$ content are given in Figure 1. Note that the pour rates have not been corrected for decreasing head.

In previous runs with normal quantities of cerium and neodymium, typically the first two samples collected exhibited a marbled or swirled appearance. In this run, the first samples were uniform and the last three samples collected showed a marbled appearance, with clearly visible swirls in the glass. Comparison with previous runs also revealed that significantly more glass $(1.25$ " height vs. $\sim 1 / 2$ " in previous runs) remained in the vessel bottom following cool down but the granular appearance was similar to that from standard $58 \mathrm{wt} \%$ lanthanide loaded, 25SrABS runs.

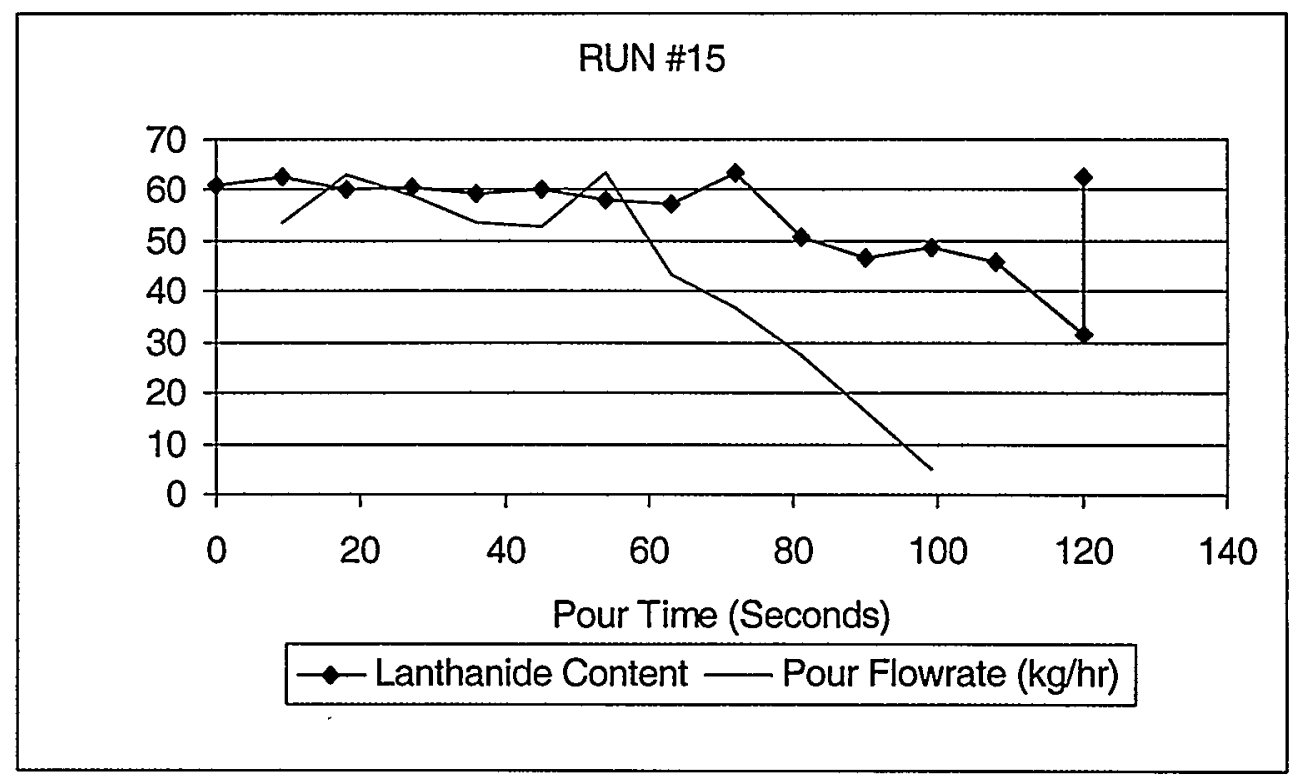

Figure 1 
WSRC-TR-99-0434

Page 7 of 59

\section{V.A.2. CIM5 Run \#16 - 58wt\% Lanthanide Loaded 25SrABS Glass With 2.0X Cerium}

To further evaluate the process effects of additional oxygen liberation, a $58 \mathrm{wt} \% \mathrm{Ln}$ glass that contained $2 \mathrm{X}$ the standard amount of cerium (replacing an equivalent quantity of neodymium) was prepared. Routine processing was observed during the calcination process and the ramp to the vitrification temperature. However, just prior to beginning the soak at $1470{ }^{\circ} \mathrm{C}$, thermocouple $1 \mathrm{~B}$ failed resulting in hardwired and software interlocks. The temperatures in the top and bottom of the melter dropped to approximately $1120^{\circ} \mathrm{C}$ and $1245^{\circ} \mathrm{C}$, respectively. Power to the melter was reestablished in a controlled manner resulting in a reheat rate between 5 and $6.8^{\circ} \mathrm{C} / \mathrm{min}$. At about $1400^{\circ} \mathrm{C}$ a volume expansion was observed evidenced by an increase in the bed and melter wall thermocouple temperature indications. The bed rose to within 2 to 3 inches of the melter top but within about 20 minutes collapsed back into the glass pool. It appears that even though the reheat was within our temperature ramp guidelines, the lower glass pool reheated quicker trapping the evolved oxygen from the cerium reduction in the colder, more viscous top layer expanding the bed.

It should be noted that the process and equipment handled the $2 \mathrm{X}$ cerium feed and the power interlock quite well. The volume expansion was easily contained in the melter vessel and was readily absorbed back into the glass pool within about 20 minutes. From the volume expansion potential, this scenario is thought to represent a worst case. As an aside, the volume expansion was quite effective in removing rare earth oxide and silicate deposits from the melter wall.

The cold glass plug dropped from the drain tube 46 seconds after the tip cooling air was shut off, followed by a steady stream of glass. Pour rate samples were collected continuously for 9 seconds each during the pour to establish a lanthanide concentration profile for the melter volume. The measured pour rates were similar to those obtained for the $1.5 \mathrm{X}$ cerium run and are shown in Figure 2. The appearance of the pour samples and the residual glass in the melter, however, were quite different. All the samples were marbled and appeared to have a more uniform loading. The residual glass in the melter was a more heavily loaded monolith in contrast to the lightly loaded, granular material in the $1.5 \mathrm{X}$ cerium and standard 58 wt\% Ln runs. This residual glass monolith appeared to result from the volume expansion. 
RUN \#16

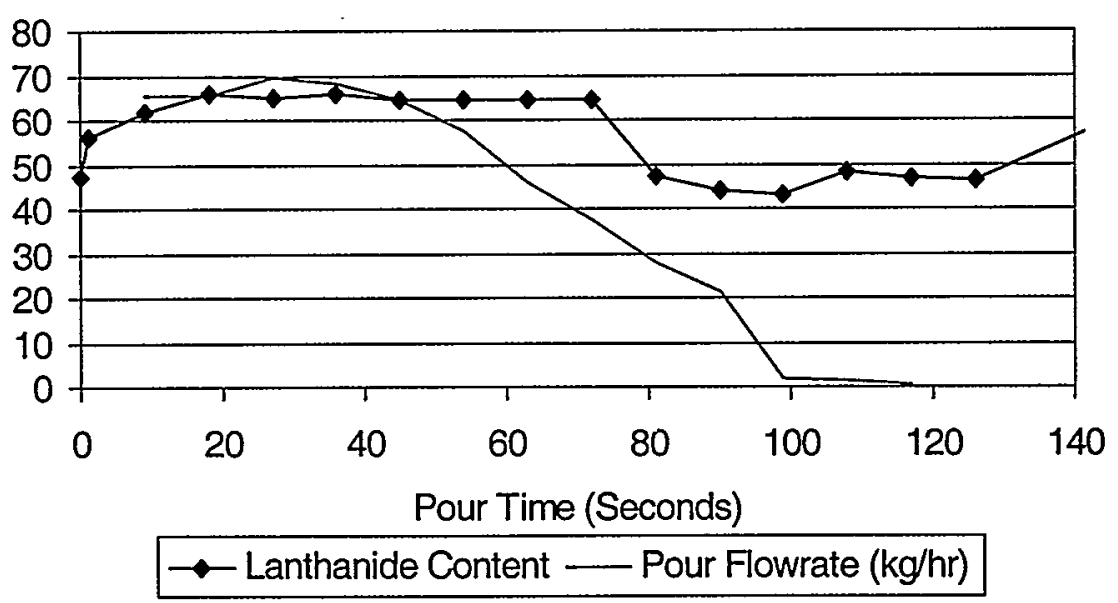

Figure 2.

\section{V.A.3. CIM5 Run \#17 - 58 wt\% Lanthanide Loaded 25SrABS Glass}

The objective of this run was to process a 58 wt\% Ln loaded glass and collect 9 second pour samples continuously during the pour to establish a lanthanide concentration profile for the drain tube and melter volume. Routine processing was observed during the drying, calcination, and vitrification phases. Pour rate data and Ln content are shown in Figure 3.

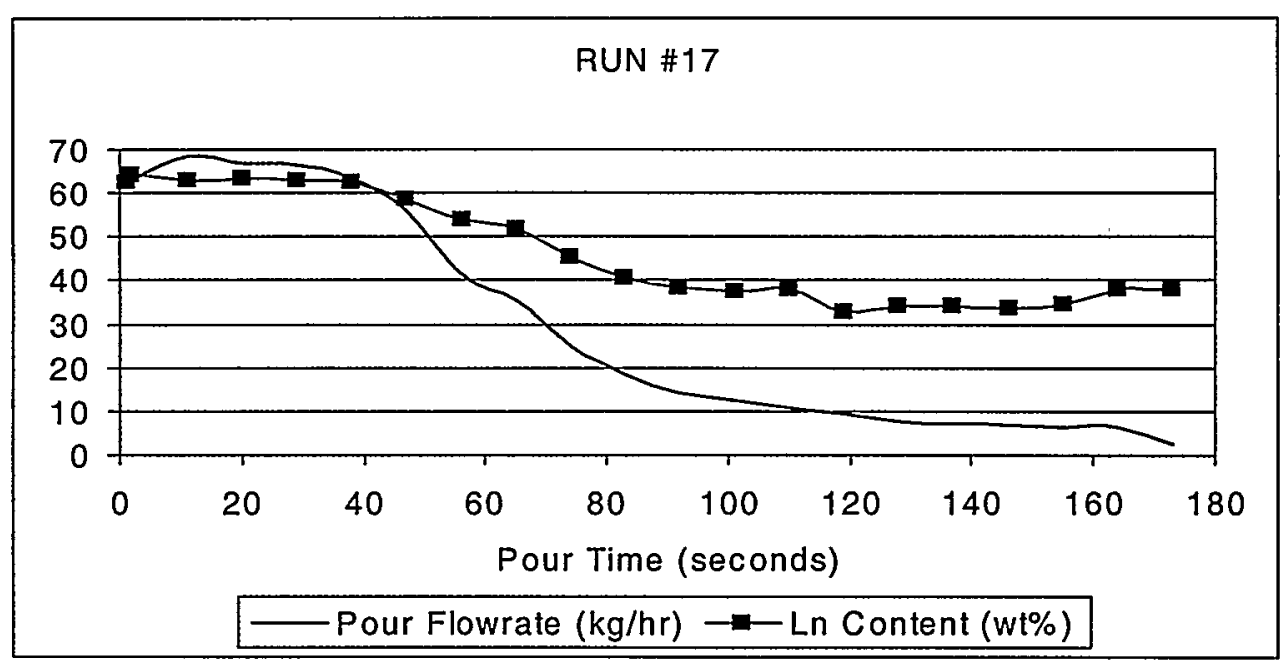

Figure 3. 
WSRC-TR-99-0434

Page 9 of 59

\section{V.A.4. CIM5 Run \#18 - 58 wt\% Lanthanide Loaded 25SrABS Glass}

This run was a repeat of Run \#17 with the same objective of collecting 9 second pour samples to establish a lanthanide concentration profile for the drain tube and melter volume. Routine processing was observed during the drying, calcination, and vitrification phases. Pour rate and composition data were similar to those in Run \#17 and are provided in Figure 4.

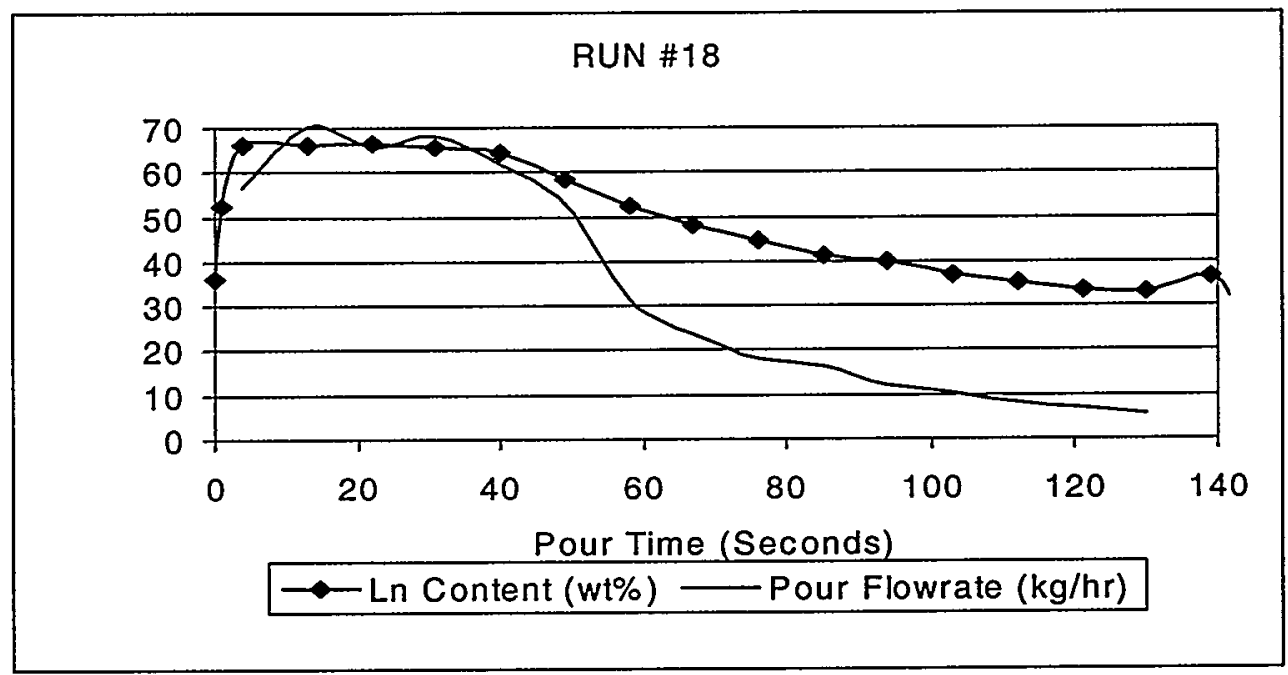

Figure 4

\section{V.A.5. CIM5 Run \#19 - 58 wt\% Lanthanide Loaded 25SrABS Glass With 2.0X Cerium}

In the previous CIM5 run-with $2.0 \mathrm{X}$ cerium (Run \#16), a volume expansion was experienced as the melter temperature approached the target soak temperature of $1450^{\circ} \mathrm{C}$ during recovery from an interlock. To further evaluate the process effects of additional oxygen liberation, the $2.0 \mathrm{X}$ cerium run was repeated so that the interlock and $2 \mathrm{X}$ cerium effects could be separated. As in Run \#16, routine processing was observed during the calcination process and the ramp to the vitrification temperature. However, as the heating cycle approached the $1450{ }^{\circ} \mathrm{C}$ peak soak temperature, a very gradual volume expansion was observed evidenced by an increase (about $50^{\circ} \mathrm{C}$ ) in the bed and melter wall thermocouple temperature indications. The bed rose to within 2 to 3 inches of the melter top but the volume expansion was easily contained in the melter vessel. The hold time after the volume expansion was absorbed back into the glass pool was about 30 minutes shorter in this run than in the previous $2 \mathrm{X}$ cerium run. This shorter hold time had a significant effect on the foam content of the glass and the glass pouring process. The final $20 \%$ of the glass dripped from the melter drain tube and was observed to 
be heavily loaded with bubbles. A longer hold time should reduce the foam and improve the pour. The volume expansion was again quite effective in removing the deposits from the melter wall.

Pour rate samples were collected continuously for 9 seconds and the results are shown in Figure 5. The appearance of the pour samples and the residual glass in the melter were quite different from the standard runs (58 wt\% Ln loading with normal cerium) and the $1.5 \mathrm{X}$ cerium run (Run \#15). All the samples were highly marbled and appeared to be very nonhomogeneous. The residual glass in the melter was a lightly loaded, foamy material.

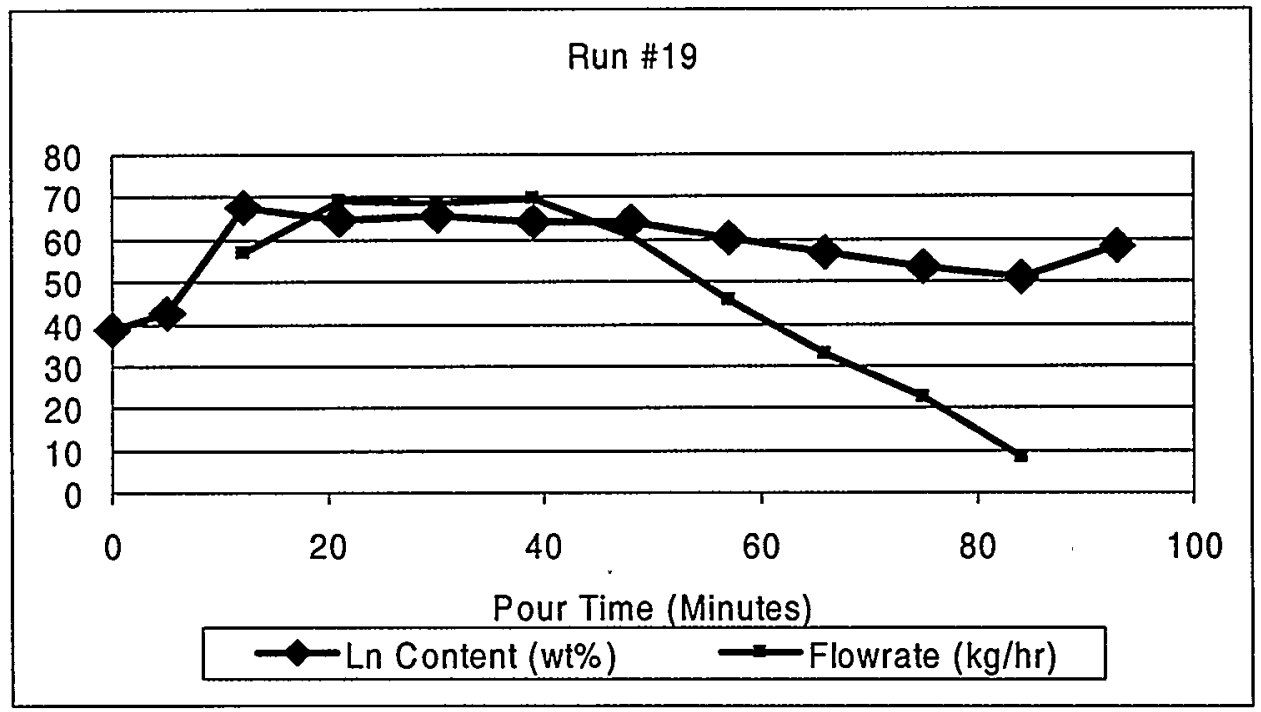

Figure 5

\section{V.A.6. CIM5 Run \#20 - 58wt\% Lanthanide Loaded 25SrABS Glass With 1.7X Cerium}

To further evaluate the process effects of additional oxygen liberation, a $58 \mathrm{wt} \% \mathrm{Ln}$ glass that contained 1.7X the standard amount of cerium was prepared. In this run the cerium replaced an equivalent quantity of erbium rather than neodymium as in previous runs. This quantity of cerium simulates the case where only americium is thermally reduced. As the heating cycle approached the soak temperature of $1450^{\circ} \mathrm{C}$, a very gradual volume expansion was again observed. The bed rose to within several inches of the melter top. The previous two CIM5 runs with 2.0X cerium (Runs \#18 and \#19). also exhibited a volume expansion as the melter temperature approached the target soak temperature.

The process and equipment handled the increased cerium feed and resulting volume expansions quite well. The volume expansions were 
WSRC-TR-99-0434

Page 11 of 59

easily contained in the melter vessel in all runs; however, foam still remained after the 60 minute soak in Runs \#19 and \#20. The melter temperature plots for Runs \#19 and \#20 (Figures 6 and 7, respectively) show that the higher temperatures, indicative of the bed expansion, returned to normal after approximately 30 minutes, which was more than half way through the 60 minute soak period. (See Attachment 2 for thermocouple locations).

The glass pour in Run \#20 was significantly affected by the foamy conditions within the melter and was similar to Run \#19. The cold glass plug dropped from the drain tube 44 seconds after the tip cooling air was shut off, followed by a steady stream of glass. Pour rate and Ln content are provided in Figure 8. The appearance of the pour samples and the residual glass in the melter were quite similar to the $2.0 \mathrm{X}$ cerium run. All the samples were marbled and appeared to be nonhomogeneous and the residual glass in the melter was a lightly loaded, granular materiàl. Significantly more residual glass was left in the melter at the end of this run.

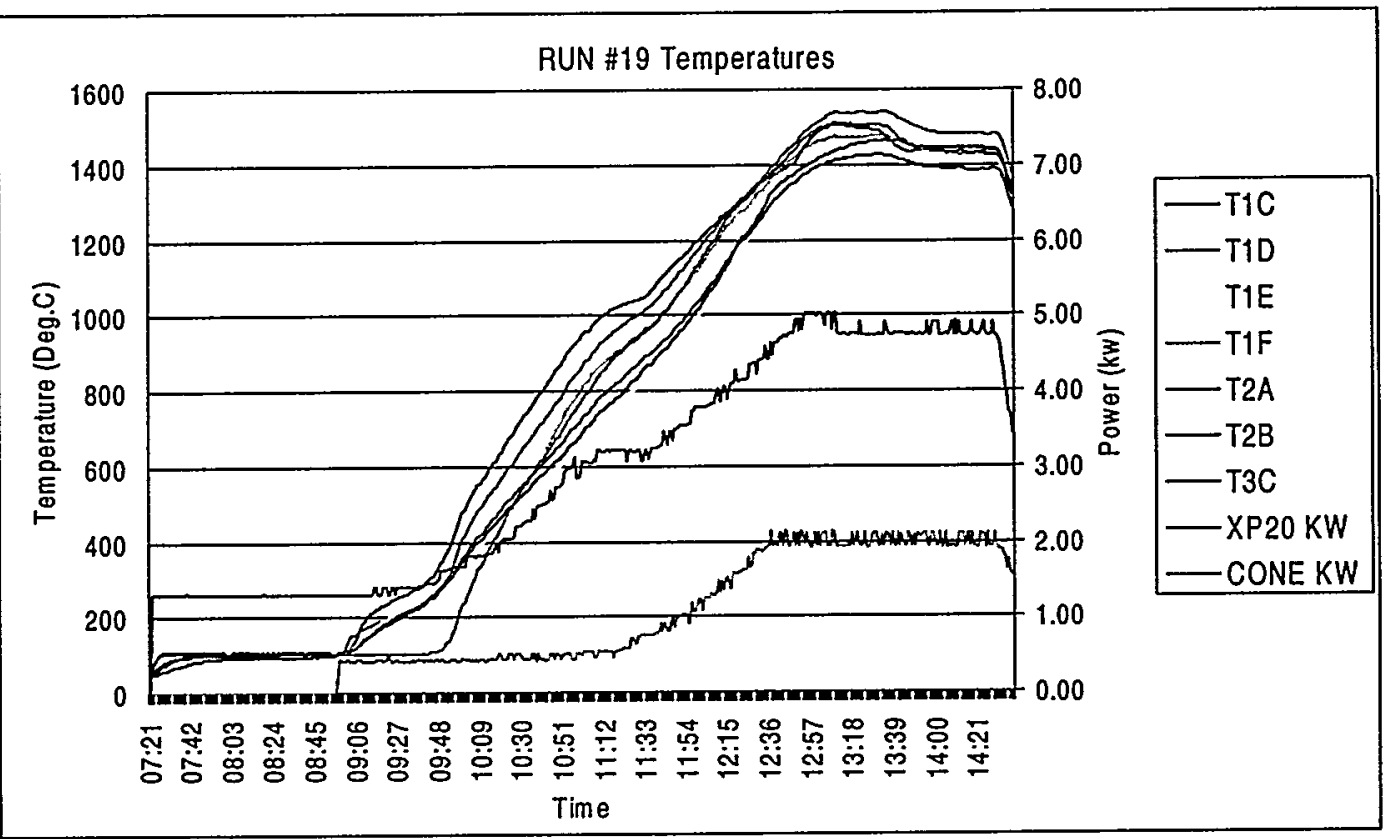

Figure 6 

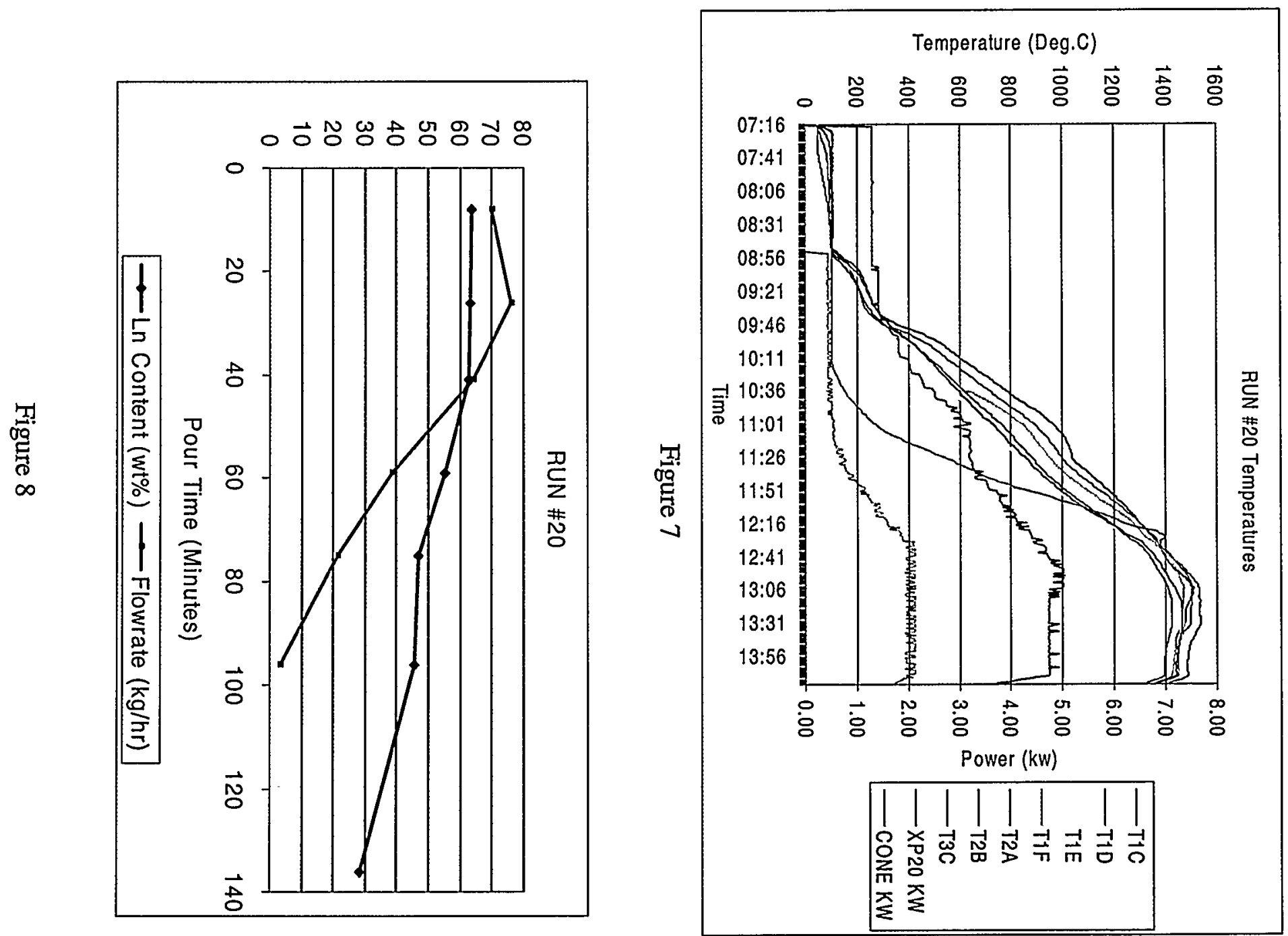

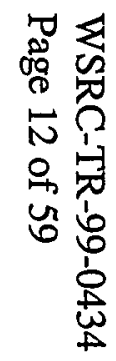


WSRC-TR-99-0434

Page 13 of 59

\section{V.A.7. CIM5 Run \#21 - 58wt\% Lanthanide Loaded 25SrABS Glass With 1.87X Cerium}

A $58 \mathrm{wt} \% \mathrm{Ln}$ glass that contained $1.87 \mathrm{X}$ the standard amount of cerium was prepared in this run. The cerium replaced an equivalent quantity of erbium and simulated the case where both americium and curium are thermally reduced: As in previous runs, a small volume expansion was observed.

Initiation of glass pouring, however was unsuccessful due to an obstruction in the drain tube that would not melt. Following initiation of the pour sequence, 5.5 grams of glass drained from the and then pouring ceased. An additional 2.0 grams were removed from the drain tube after insulating the lower part of the tube to reduce heat losses. This sample appeared surrogate rich. After several hours of additional heating and several unsuccessful pour initiation attempts, the decision was made to shut down the melter. The 7.5. grams of glass removed would have inventoried about $65 \%$ of the volume of the drain tube (assuming a solids density of 3.7 grams/cc).

\section{V.A.8. Plugged Drain Tube Recovery}

Raytheon $\mathrm{x}$-rayed the tube using an iridium source to determine the distribution of glass in the tube. The $x$-ray showed a $3 / 4$ inch plug in the tip of the tube', about a 3 inch void volume, and another plug in the top 2 $1 / 4$ inches of the tube. The three glass samples recovered from the attempted pour (initial drain tube tip plug, drain tube contents recovered from the bucket of water, and final tip plug ) were analyzed using SEMM. Results on the first two samples, the initial drain tube tip plug and drain tube contents, indicated the plugs consisted primarily of rare earth silicates with very little glass phase present. The final tip plug, however, consisted of alumino silicates with very little lanthanide present. These results represent two: extremes, high lanthanide loading which devitrified to produce rare earth silicates and low lanthanide loading that may have devitrified to form alumina silicates. Devitrification at the lower lanthanide loading had not been extensively investigated. Therefore, work to provide additional liquidus information and crystallization kinetics was started.

Several options to unplug the tube were considered including dissolution, mechanical means, and thermal shock. Before attempting to dissolve the material in the drain tube tip, dissolution of a sample of the glass removed from the drain tube was attempted in the laboratory using $50 \% \mathrm{HNO}_{3}$ and IM HF solution at room temperature. After 24 hours about 7\% of the 
material dissolved. The remaining material appeared to be a sintered oxide $(80 \%)$ and a gelatinous material (20\%), perhaps a silica compound or $\mathrm{SrF}$ which is insoluble. These results indicated dissolution of the actual drain tube plug was not practical.

An option to heat the drain tube at a fast rate to utilize the differences in thermal expansion between the platinum tube and plug and the propensity of the plug to crack under high temperature gradients was attempted next. The drain tube induction power input was set to the normal operating peak output $(1.02 \mathrm{kw})$ to quickly heat the drain tube to $1000^{\circ} \mathrm{C}$, then the drain tube cooling air was applied to quench the tube in an attempt to dislodge the obstruction. When inspection of the plug showed no change as a result of the thermal conditioning, the process was repeated to allow the drain tube to heat to $1200{ }^{\circ} \mathrm{C}$. Again, there was no evidence of change to the plug upon cooldown and visual inspection.

Equipment Engineering Services identified equipment that could be used to drill out the plugged drain tube without having to remove the melter from the pilot facility. A flexible shaft drill motor fitted with diamond coated grinding burrs and carbide drill bits was used to carefully remove the 3/4" plug in the lower end of the drain tube. The material was quite hard and because of our inability to cool the cutting tools, resulted in short tool life $(<1$ minute). Approximately 16 burrs and 3 carbide bits were needed to remove the plug.

A special run plan was used to remelt the Run \#21 glass in the CIM5 vessel, pour the glass, and then flush with $50 \mathrm{SrABS}$ cullet. The residual glass from Run \#21 was heated at 15 to $20^{\circ} \mathrm{C} / \mathrm{min}$ to $1480^{\circ} \mathrm{C}$, then the drain tube was quickly brought to temperature without tip cooling air present. The three initial plugs that dropped from the drain tube were collected for subsequent analyses. Approximately 90 seconds later, a steady glass stream was obtained.

After pouring was completed, and with the melter still powered and at temperature, about 340 grams of 50SrABS cullet was added to flush the vessel and drain tube. Without tip cooling air applied, this glass began to drain from the tube within about 4 minutes. At the completion of draining, the drain tube cooling air was applied. Another 340 grams of 50SrABS was added to the hot melter and allowed to soak for 30 minutes after reaching the $1480^{\circ} \mathrm{C}$ target temperature. Following the soak, glass pouring was initiated and the vessel and drain tube were completely drained. An additional 25 grams of 50SrABS cullet was fed to the melter to provide a glass plug in the drain tube of known composition in preparation for future melter runs. 
WSRC-TR-99-0434

Page 15 of 59

The inside diameter of the drain tube was slightly enlarged from the drilling operation and appeared to adversely affect droplet disengagement. Approximately $1 / 4$ inch was removed from the tube to restore a sharp edge bottom, returning the tube to its original 6 inch length.

\section{V.A.9. CIM5 Run \#22 - 58 Wt\% Ln Loaded 25SrABS Glass Produced from Glass Beads}

This run processed a $25 \mathrm{SrABS}$ glass loaded to $58 \mathrm{wt} \%$ lanthanide with a standard oxalate slurry. In contrast with previous CIM5 runs, 1/4 inch diameter marbles were used in place of cullet. The marbles were previously evaluated on the Drain Tube Test Stand and had resulted in a volume expansion in contrast to processing with cullet. The residual glass in the melter and drain tube prior to beginning the run was 50SrABS used as a melter flush after Run \#21 was drained.

Drying, calcination, and the ramp to the vitrification temperature proceeded normally. Based on melter wall temperature observations, a very small volume expansion occurred but was of no consequence. About 5 minutes into the hold period at the target vitrification temperature an inadvertent pour occurred. A drain tube plug about 1-1/2 inches long dropped into the bucket under the drain tube. Holding air flow directed at the tip of the tube was increased to prevent reoccurrence. Approximately 15 minutes into the hold period a drain tube temperature interlock occurred. Because of a suspected control system communication error, difficulties were encountered in clearing the interlock and resuming induction heating. Melter temperatures dropped into the 550 to $600^{\circ} \mathrm{C}$ range. After recovery to the target temperature and a suitable hold at temperature, pouring was attempted but was unsuccessful. A plug, which appeared to be highly loaded glass, was removed from the tube tip. Probing revealed another soft, moveable plug about 1-1/2 inches up from the tip. However, a short time later when this plug reached the tip, probing revealed it was hard and immovable.

After cooling the melter to room temperature, Raytheon again $\mathrm{x}$-rayed the tube to determine the distribution of glass. The $x$-ray showed a 1/8 inch plug in the tip of the tube, a 2-1/2 inch void volume, a 3/8 inch long plug, a 1-1/2 inch void volume, and a 1-1/2 inch plug in the top of the tube. The bottom plug was successfully drilled out and a rapid melter heatup program was successfully performed to drain the melter contents as was done after mechanically removing the Run \#21 tip plug. 
WSRC-TR-99-0434

Page 16 of 59

\section{V.A.10.CIM5 Runs \#23, \#24, and \#25 - 58wt\% Lanthanide Loaded $25 S$ SrABS Glass}

After recovery from the Run \#22 drain tube plug, there was a concern that damage to the inside diameter of the drain tube (surface roughness or a burr) caused by drilling the plugs may act as a nucleation site promoting crystal growth. To assess potential damage to the inside diameter of the drain tube, two standard runs using $25 \mathrm{SrABS}$. cullet with 58 wt\% lanthanide loading were completed (\#23 and \#24). Prior to the first run (\#23), the melter was drained and a 30STABS heel was placed in the melter to better simulate the residual glass left after a pour. Both runs used oxalate precipitate that was produced in CP-2, the new electropolished precipitator, rather than CP-1 which has been used previously.: Both runs were processed satisfactorily with no glass pouring problems encountered. Pouring began within one minute after initiation and produced the characteristic decreasing pour rate curve as a function of time! Based on the success of these two pours it was determined that there was not any significant damage to the drain tube.

Two processing differences were noted during this run, however. Removal of the free water during drying (determined by visual observation of the melter interior) took about 5 minutes longer than normal and at the same power inputs during vitrification, the CIM wall and glass temperatures were 30 to $50{ }^{\circ} \mathrm{C}$ lower than normal. The CP-2 oxalate batches used in these runs were collected and stored for several days in a plastic bottle allowing the oxalate to settle. Although the free liquid height in the CIM after oxalate precipitate charging was the same as in previous CP-1 runs, the solids bed height was lower indicating a more densely settled bed. Presumably no additional liquid was present, just more of it was now free liquid above the top of the solids bed.

Equipment problems for the lower vitrification temperatures were investigated but with no success. The thermocouple calibrations checked out satisfactorily and the coil voltages and the instrumentation for power, voltage and current were unchanged from previous runs. It was suspected that the absence of bubbles or foam formation in these runs was responsible for the lower temperatures. This behavior was seen previously when the CIM recovered from an interlock (i.e. foam acted as an insulator).

To generate additional information to explain these processing differences, a third standard run was made using $25 \mathrm{SrABS}$ cullet and CP-1 oxalate loaded to $58 \mathrm{wt} \%$ (\#25). Drying time returned to normal, which tended to support the above explanation for free water. Melter temperatures, however, were still approximately $30^{\circ} \mathrm{C}$ lower than normal. The melter 
WSRC-TR-99-0434

Page 17 of 59

temperature is plotted in Figure 9 and the pour rate and Ln content are given in Figure 10.

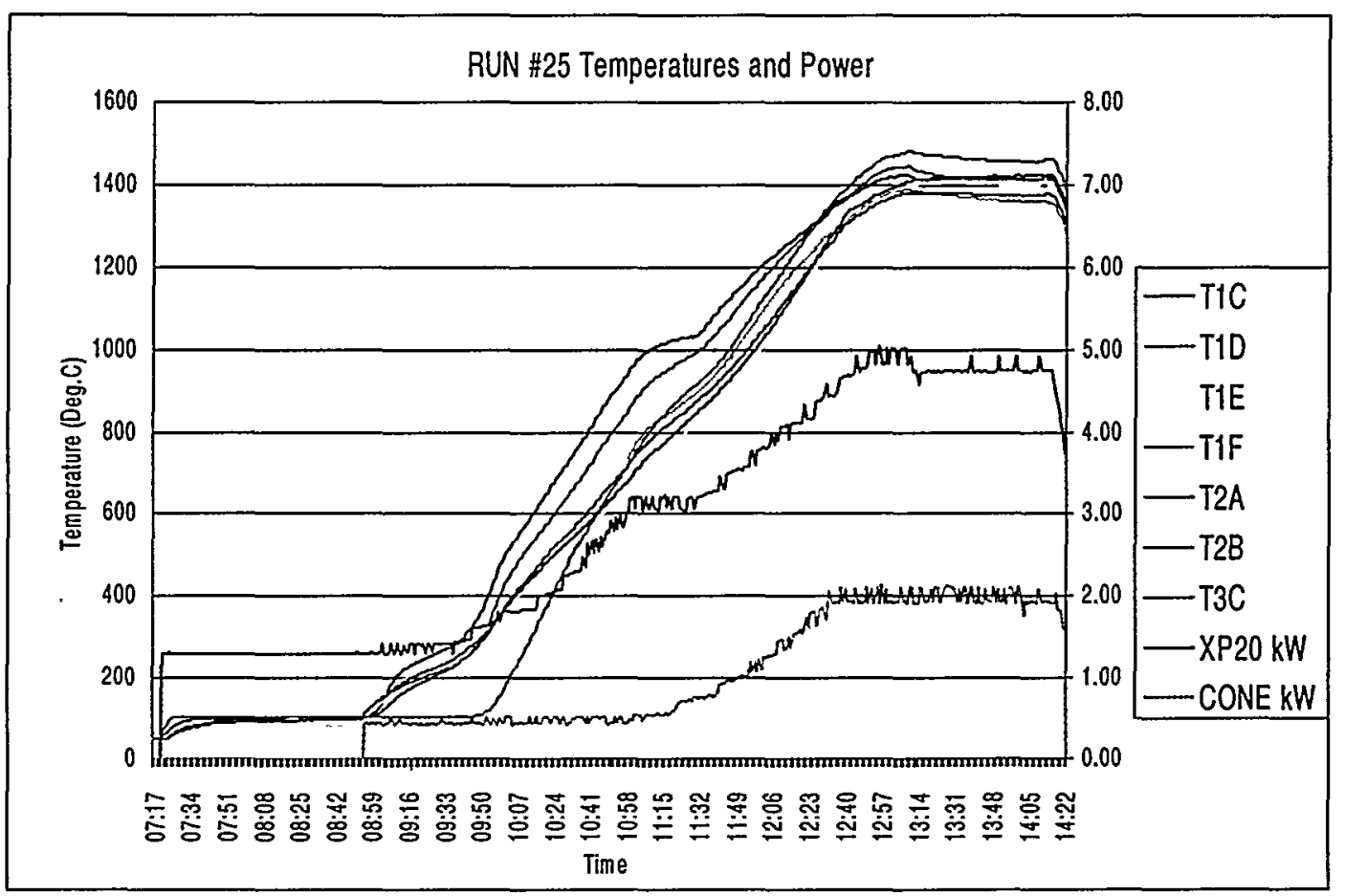

Figure 9

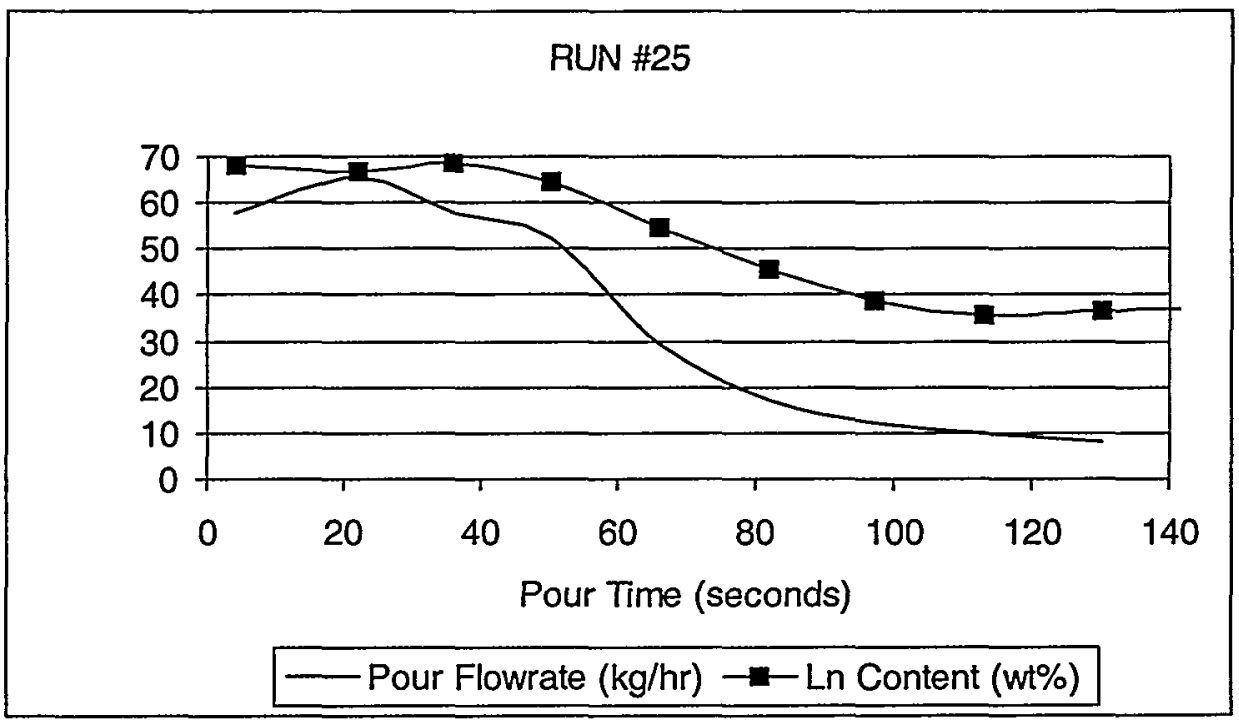

Figure 10 
WSRC-TR-99-0434

Page 18 of 59

\section{V.A.11. Drain Tube Pluggage Analysis}

Detailed analysis of the glass composition, process conditions, operating parameters, and events associated with the previous two runs that resulted in plugs was performed. Information from previous CIM5 runs that gave pouring difficulty as well as the DTTS run that resulted in a plugged drain tube were included in this study. Chemical analyses showed that for a 58 wt\% Ln loaded glass, the initial pour sample from a normal run typically varied between 63 and $70 \mathrm{wt} \%$ lanthanide. The lanthanide content fell to $\sim 40 \mathrm{wt} \%$ during the pour and the heel remaining in the melter was typically less than $32 \mathrm{wt} \%$. The high Ln loaded glass, which resided in the bottom conical section of the melter, was found in laboratory work to have a liquidus temperature in the $1350^{\circ} \mathrm{C}$ range and displayed very rapid crystallization kinetics. Therefore, off normal conditions (e.g. volume expansion or interlock) or even temperature gradients could trigger conditions conducive to forming drain tube plugs. For these reasons, processing of a $58 \mathrm{wt} \% \mathrm{Ln}$ loaded 25 SrABS glass was not considered to be acceptable and evaluation of lower Ln loadings was initiated.

\section{V.B. Evaluation of Lower Lanthanide Loadings to Mitigate Drain Tube Plugging}

A potential solution to the plugging problem from the glass chemistry standpoint involved decreasing the target lanthanide $(\mathrm{Ln})$ loading. However, at the lower $\mathrm{Ln}$ loadings a rather large heel of high viscosity glass remained in the melter after a pour. To reduce the size of this glass heel a higher lanthanum content cullet (e.g. $30 \mathrm{SrABS}$ or $35 \mathrm{SrABS}$ ) was also chosen for evaluation to increase the residual $\mathrm{Ln}$ content and, hence decrease the viscosity.

Subsequent runs began investigating lower lanthanide loadings beginning with 50 wt\% Ln and progressing through 47, 52 and $55 \mathrm{wt} \%$ runs. Duplicate runs were made at each $\mathrm{Ln}$ loading to verify reproducibility. All runs yielded favorable results. Glass pour initiation was reproducible, the pour rates were consistent, and glass quality was good for each run. The $49 \mathrm{wt} \% \mathrm{Ln}$ loaded $25 \mathrm{SrABS}$ glass was chosen as the preferred composition because it provided sufficient operating room to reduce the potential for devitrification while maintaining the desired viscosity at the target operating temperature.

Higher lanthanum content cullet (30SrABS and 35SrABS) was then evaluated with the best lanthanide loading candidate from the above series, the $49 \mathrm{wt} \% \mathrm{Ln}$ glass. The cullet for the $30 \mathrm{SrABS}$ and $35 \mathrm{SrABS}$ was produced from batch chemicals in CIM5. Both the 30SrABS cullet and 35SrABS cullet resulted in significant volume expansions during processing. The lower softening 
temperature resulting from the additional lanthanum in the cullets interacted with the oxygen released from cerium reduction to increase the volume expansion severity.

\section{V.B.1 CIM5 Runs \#26 and \#27 - 50 wt\% Lanthanide Loaded 25SrABS Glass}

Runs \#26 and \#27 produced 50 wt\% Ln loaded 25SrABS glass. The automatic power control program was used for these runs except that the vessel coil power was maintained at $5.02 \mathrm{kw}$ for the duration of the soak, rather than being reduced to $4.75 \mathrm{kw}$ as had been the practice in previous runs to avoid overshooting the target vessel soak temperature. There was no evidence of foaming or bed expansion during either of these runs. The glass plug that remained in the bottom of the melter after each pour was lightly loaded, bubble free, clear glass. Pour initiation for each run was typical, with pour rates near $70 \mathrm{~kg} / \mathrm{hr}$ initially, decreasing due to loss of head and lower loading (i.e. higher viscosity) as the pour progressed. The pour rate data and Ln content are plotted in Figure11 for Run \#27. Visual inspection of the glass showed no evidence of devitrification in any of the samples.

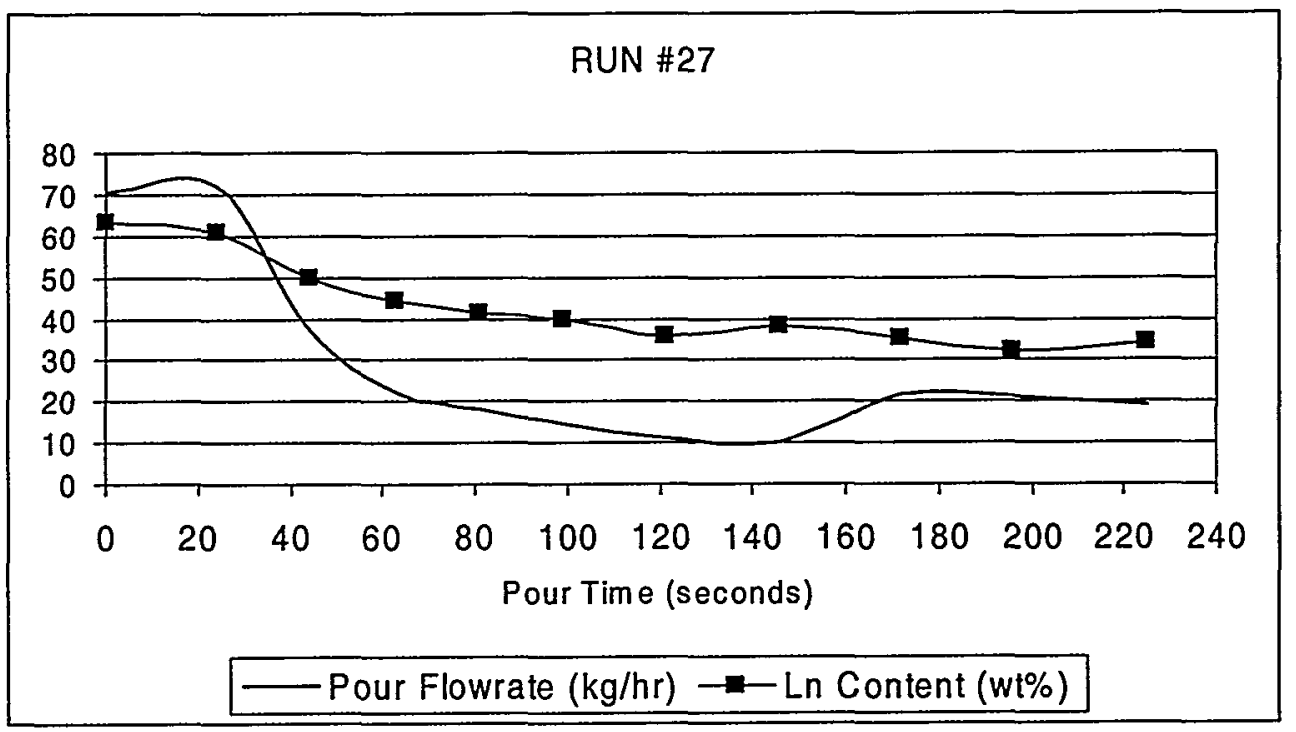

Figure 11 


\section{V.B.2. CIM5 Runs \#28 and \#29 - 47 wt\% Lanthanide Loaded 25SrABS Glass}

Run \#28 produced a $47 \mathrm{wt} \% \mathrm{Ln}$ loaded $25 \mathrm{SrABS}$ glass using precipitate from CP1. The CIM5 vessel contained a residual $1 / 4$ " high, bubble free glass plug from the previous $50 \mathrm{wt} \% \mathrm{Ln}$ run. The free liquid was boiled away within 86 minutes. The glass plug began extruding from the drain tube 43 seconds after removal of the tip cooling air and the pour stream was established 7 seconds later. The samples collected showed the typical evidence of higher Ln loading at the beginning of the pour with decreasing loading at the end of the pour. There was no evidence of the swirled marbled appearance in any of the samples. The residual glass remaining in the melter at the conclusion of the pour was about 1/8" high and was bubble free and clear in appearance.

Run \#29 was a follow-up to Run \#28 producing another 47 wt\% Ln loaded 25SrABS glass. Oxalate precipitate from CP2 was used for this run. The free liquid was boiled away within 92 minutes. Forty five seconds after removal of the tip cooling air, the glass plug began extruding from the drain tube. Pour rate and Ln content data are shown in Figure 12. As with the previous $47 \mathrm{wt} \%$ run, the samples collected showed the typical high loading at the beginning of the pour and lower loading at the end. No swirled marbled appearance was noted. The residual glass remaining in the melter at the conclusion of the pour was bubble free and clear in appearance, measuring about $1 / 8$ " in height.

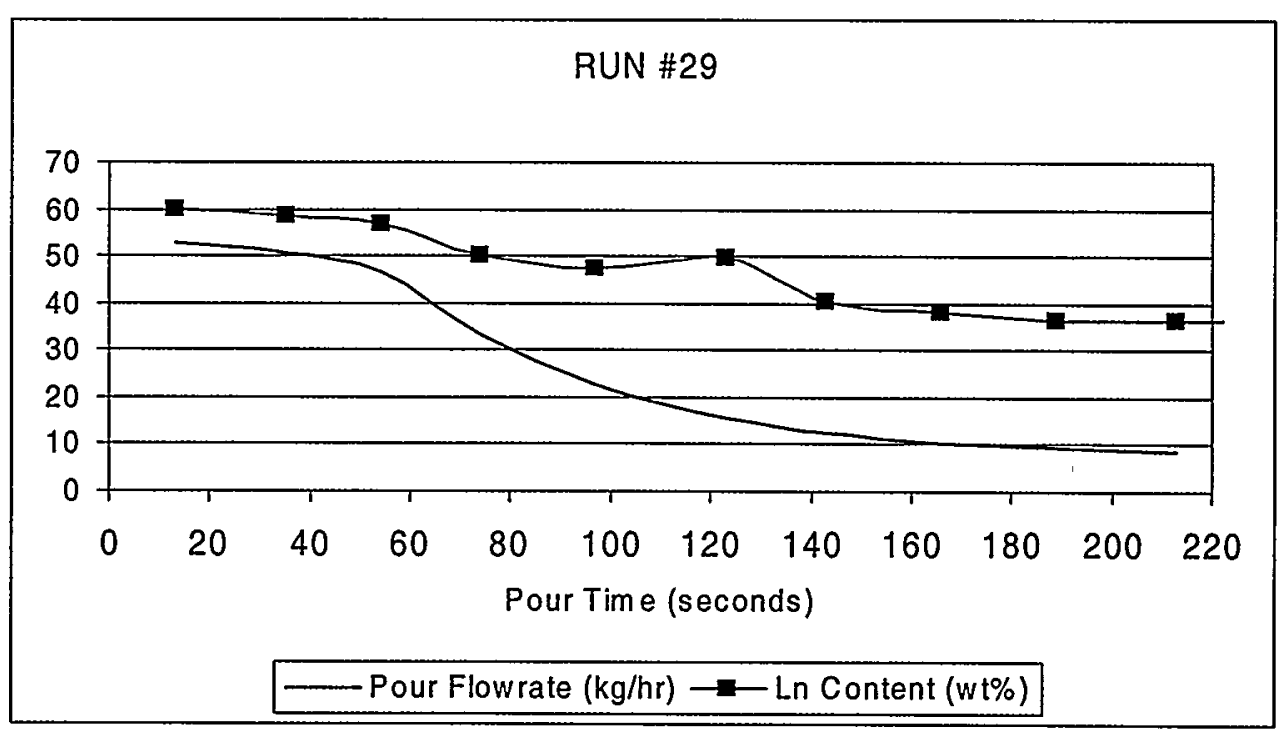

Figure 12 
WSRC-TR-99-0434

Page 21 of 59

\section{V.B.3. CIM5 Runs \#30 and \#31 - 52 wt\% Lanthanide Loaded 25SrABS Glass}

Run \#30 produced a $52 \mathrm{wt} \% \mathrm{Ln}$ loaded glass using oxalate precipitate from CP2. Free liquid drying was completed in 93 minutes. Observed Ln loadings were typical of the previous $47 \mathrm{wt} \%$ runs and no swirled marbled appearance was noted. Residual glass remaining in the melter was foamy and milky white in appearance in contrast to the four previous runs (50 and $47 \mathrm{wt} \% \mathrm{Ln}$ loaded glass).

Run \#31 was a repeat of Run \#30, producing a $52 \mathrm{wt} \%$ Ln loaded $25 \mathrm{StABS}$ glass. Free liquid drying was completed in 88 minutes. Plug extrusion began 36 seconds after pour initiation. Nine second pour samples were taken and Figure 13 displays the pour rate and Ln content data. Residual glass remaining in the melter was again foamy and milky white in appearance, measuring $1 / 2$ " in elevation.

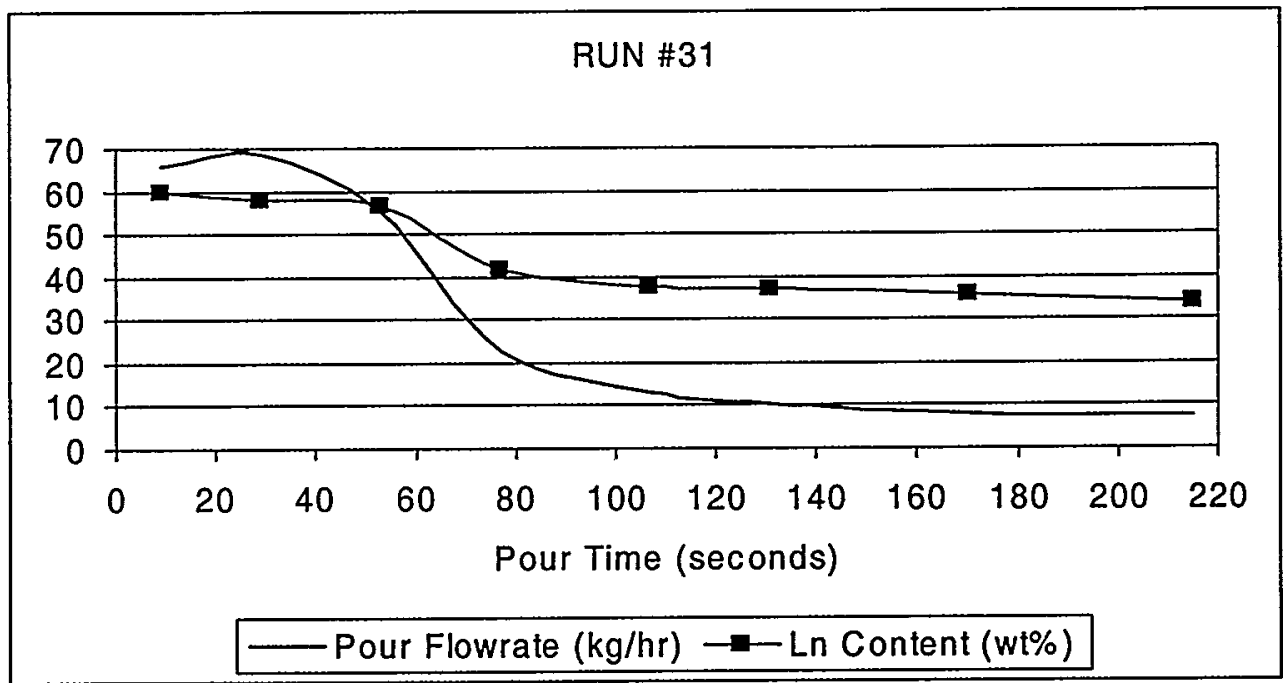

Figure 13

\section{V.B.4. CIM5 Runs \#32 and \#33 - 55 wt\% Lanthanide Loaded 25SrABS Glass}

Runs \#32 and \#33 produced 55 wt\% Ln loaded glass with oxalate precipitate from CP1. Free liquid drying was completed in 90 minutes with both runs. No evidence of a bed expansion was indicated with either run. . The glass plug dropped and a pour stream was established for both runs approximately 42 seconds after the tip cooling air was. Pour rate and 
Ln content data for Run \#33 are shown in Figure 14. Residual glass remaining in the vessel cone bottom following both runs measured 1" and was granular and clear in color, indicating very little loading.

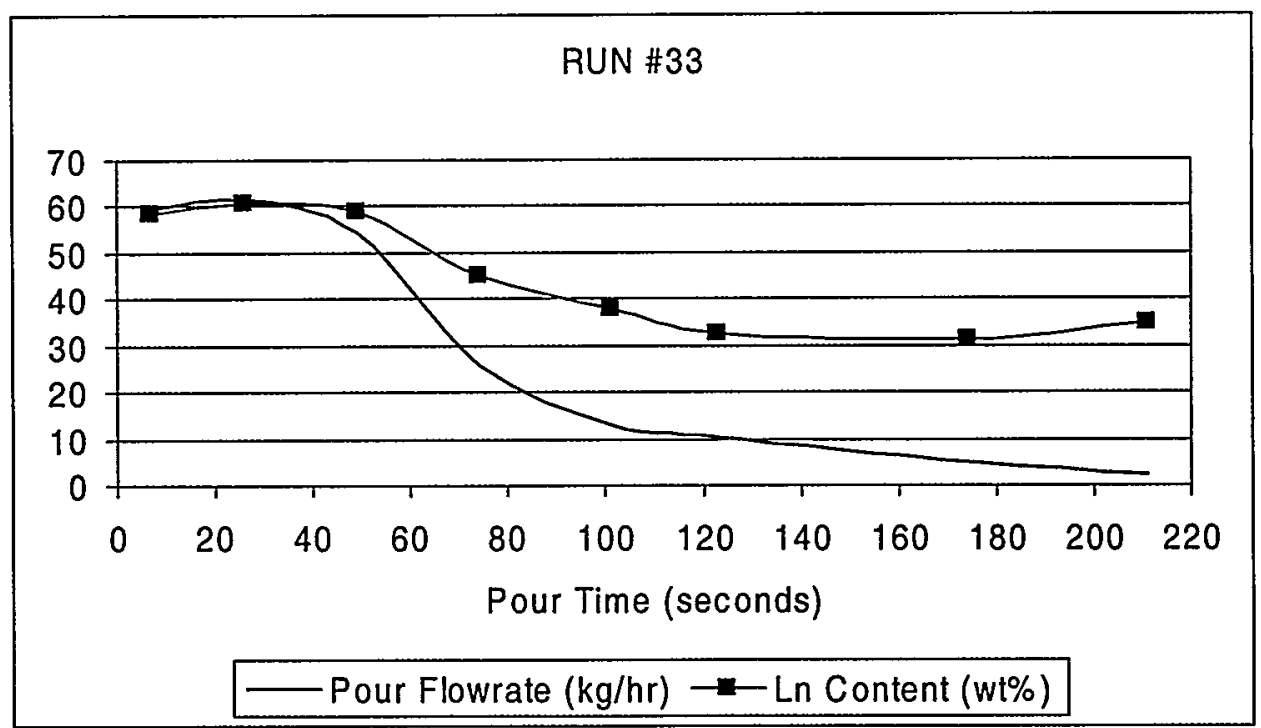

Figure 14

\section{V.B.5. CIM5 Runs \#34 and \#35 - 50 wt\% Lanthanide Loaded 25SrABS Glass}

Runs \#34 and \#35 produced $50 \mathrm{wt} \% \mathrm{Ln}$ loaded glass with oxalate precipitate from $\mathrm{CP} 1$ and $\mathrm{CP} 2$; respectively. Free liquid drying was completed in 90 and 95 minutes, respectively. No evidence of a bed expansion was indicated in either run. The glass plug dropped and a pour stream was established 32 and 49 seconds after the tip cooling air was removed for Run \#34 and \#35, respectively. Residual glass remaining in the vessel cone bottom following Run \#34 consisted of 1/4" of lightly colored, monolithic glass containing large bubbles, unlike the granular appearance of the $52 \mathrm{wt} \%$ and $55 \mathrm{wt} \%$ runs. The residual glass remaining in the vessel cone bottom following Run \#35 also consisted of $1 / 4$ " of glass, darker in color and with larger bubbles than Run \#34.

\section{V.B.6. Preferred Lanthanide Loading}

A $49 \mathrm{wt} \% \mathrm{Ln}$ loaded $25 \mathrm{SrABS}$ glass was selected as the preferred product, based upon the reduced potential for product devitrification, the behavior of the batch during the calcination and vitrification processes, and the pouring initiation behavior. There was no appreciable bed volume 
expansion during the vitrification processes for either the $47 \mathrm{wt} \%, 50 \mathrm{wt} \%$ or $52 \mathrm{wt} \% \mathrm{Ln}$ glass batches at normal cerium levels. The glass pouring initiation for each of these batches was consistently attained within 50 seconds of tube cooling air removal. The residual glass plug remaining in the bottom of the vessel following completion of each pour was a lightly loaded (as indicated by color), bubble free monolith. A loading of $49 \mathrm{wt} \%$ Ln was selected as the targeted base loading because it was mid-range between the 47 and $52 \mathrm{wt} \%$ loading.

\section{V.B.7. CIM5 Runs \#36 and \#37 - 49 wt\% Lanthanide Loaded 25SrABS Glass with Power Interlock}

Two interlock runs at $49 \mathrm{wt} \% \mathrm{Ln}$ loading were made to evaluate process recovery from off-normal conditions. The melter power was interlocked off at the start of the one hour soak period (nominal melter temperature of $1425^{\circ} \mathrm{C}$ ). In Run \#37 the power was restored to the system after about 17 minutes resulting in a larger process temperature drop than in Run \#36 (to $1000{ }^{\circ} \mathrm{C}$ versus approximately $1125^{\circ} \mathrm{C}$ in Run \#36). No adverse consequences were noted during the recovery in either run. Figure 15 shows the pour rate and Ln content data for Run \#37. A 3/8" glass heel containing several bubbles was left in the vessel bottom. It should be noted that previous power interlocks at higher Ln loading ( $58 \mathrm{wt} \%$ ) resulted in drain tube plugs, requiring mechanical removal of the material before processing could be resumed.

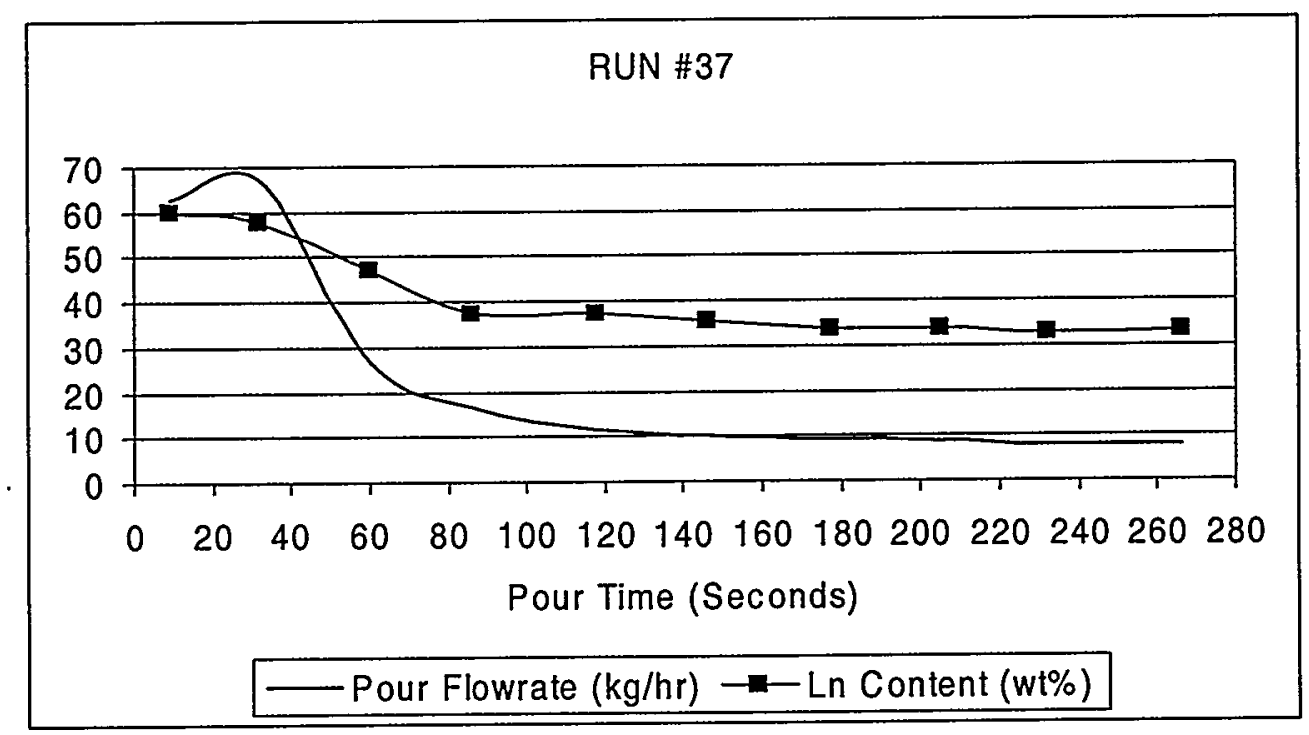

Figure 15 
WSRC-TR-99-0434

Page 24 of 59

\section{V.B.8. CIM5 Runs \#38 and \#39 - 49 wt\% Lanthanide Loaded 25SrABS Glass} Made With 1/4" Glass Beads

The goal of Run \#38 was to evaluate the process effects of using $1 / 4$ " $25 \mathrm{SrABS}$ glass beads in place of cullet. Previous glass bead evaluations in the Drain Tube Test Stand resulted in volume expansions under standard operating conditions. In Run \#38 the $25 \mathrm{SrABS}$ glass beads and oxalate precipitate were charged to the CIM vessel to produce a $49 \mathrm{wt} \% \mathrm{Ln}$ loading. The drying and calcination processes proceeded as expected. However, a small volume expansion was observed during vitrification. Vessel and bed temperatures, which are shown in Figure 16, increased 40 to $50^{\circ} \mathrm{C}$ above normal. The residual glass remaining in the melter at the conclusion of the pour was a lightly loaded glass phase containing a number of small bubbles as seen in previous $49 \mathrm{wt} \% \mathrm{Ln}$ runs. As shown in Figure 17, typical lanthanide loading variations were observed with the first samples highly loaded and decreasing as the pour progressed.

Run \#39 was the second run to evaluate the process effects of using $1 / 4$ " 25 SrABS glass beads in place of cullet. The drying and calcination processes proceeded as expected. However, a small volume expansion was again observed during vitrification, consistent with Run \#38 results. Based on the results of these two glass bead runs, no further testing using glass beads was planned. The glass beads were subsequently used as feed stock to produce $25 \mathrm{SrABS}$ cullet needed for TTR testing.

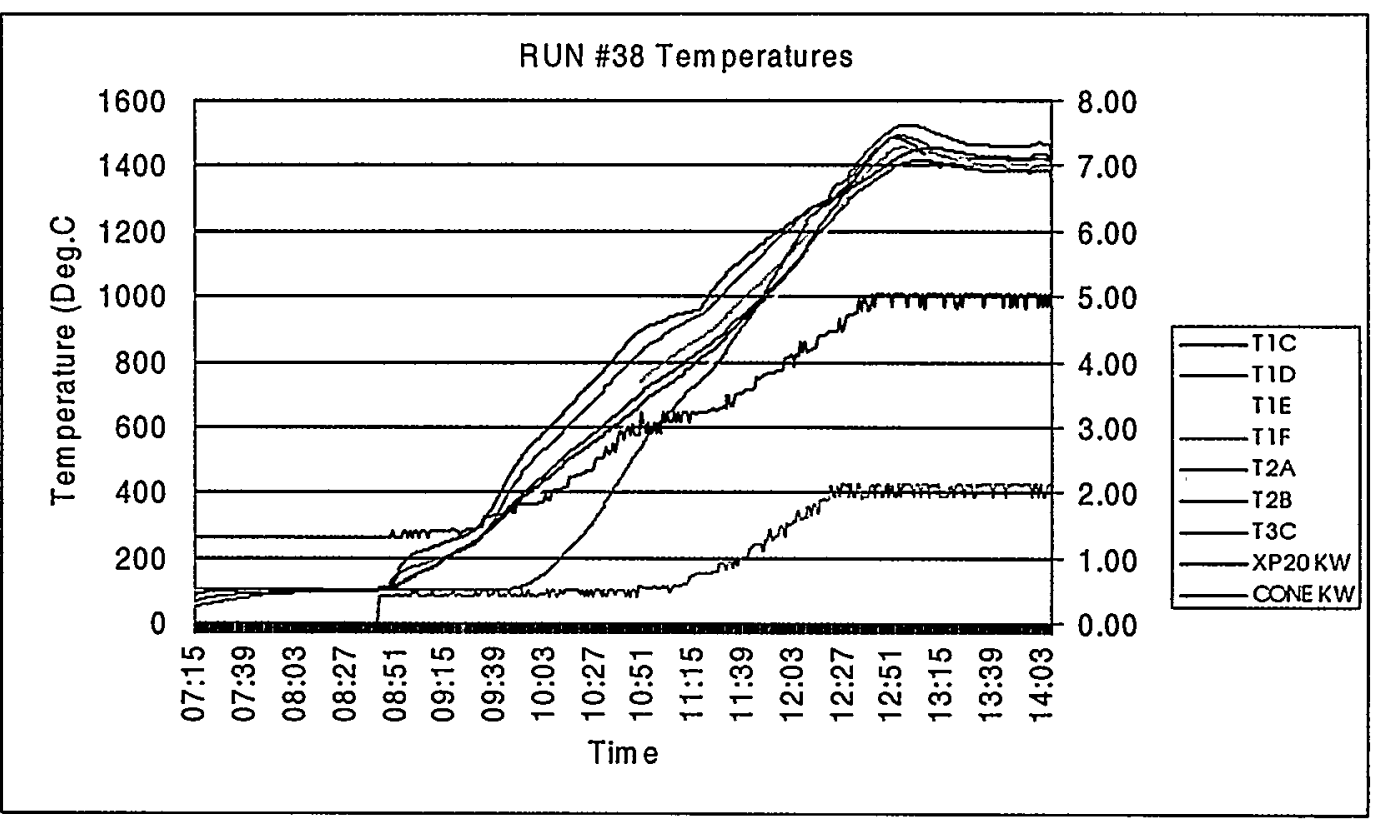

Figure 16 


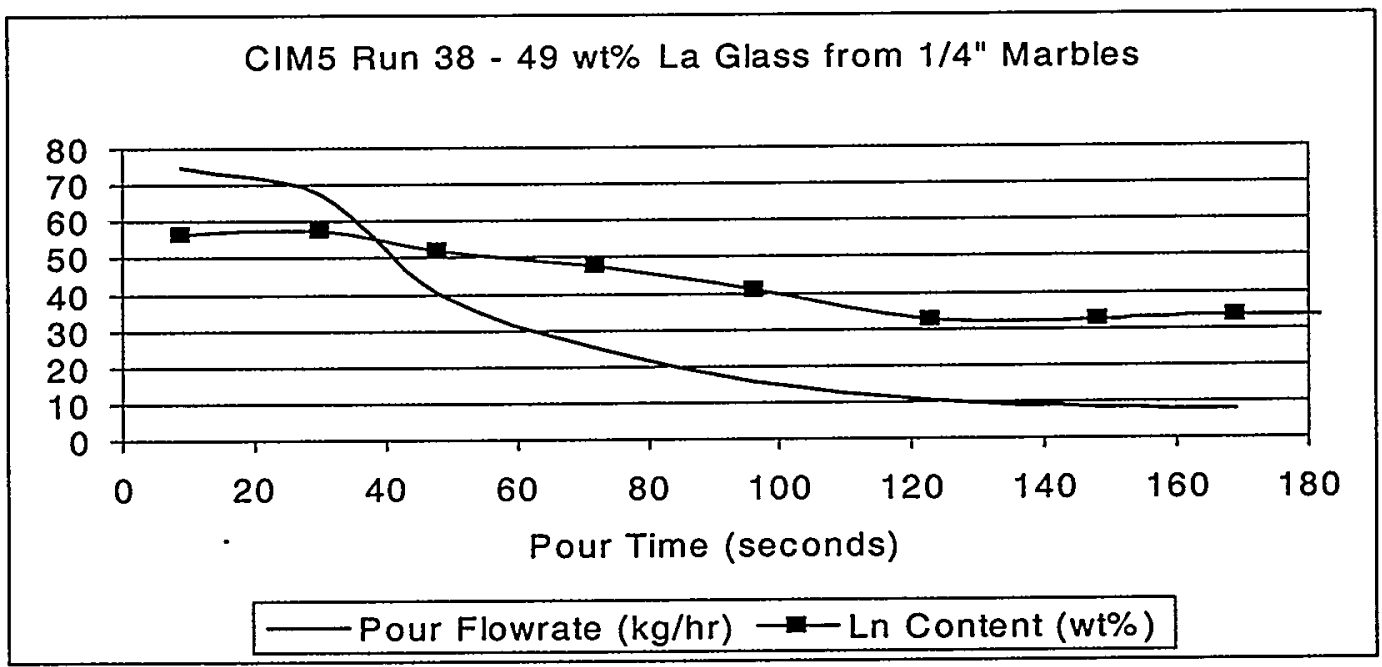

Figure 17

\section{V.B.9. CIM5 Runs 30-1, 30-1, and 35-1 - 30SrABS and 35SrABS Cullet Production}

Prior to beginning cullet production, the CIM was flushed with 1000 grams of 30SrABS batch chemicals in preparation for the first of two 1,800 gram cullet production runs. The 1000 gram flush was added to the melter and ramped at $8{ }^{\circ} \mathrm{C}$ per minute to a temperature of $1500{ }^{\circ} \mathrm{C}$. A small amount of entrainment occurred throughout the heatup, leading to a 1.8 INWC increase in HEPA differential pressure, presumably attributable to thermal decomposition of the boric acid component. The pour went smoothly and produced cullet similar in appearance to the $25 \mathrm{SrABS}$ cullet currently used.

The HEPA was changed out prior to the first production run, CIM 30-1, and boron oxide was used in place of boric acid to makeup the batch. This run went smoothly with no entrainment of material noted during the run. The pour initiated quickly and the initial pour rate was approximately 20 $\mathrm{kg} / \mathrm{hr}$. The pour was terminated after the drips were approximately 4 seconds apart, leaving the melter cone filled with a very porous, foamy material.

The second run to produce $30 \mathrm{SrABS}$ cullet, CIM 30-2, was also performed by adding 30SrABS batch chemicals to the melter. The material was heated at low power to remove any moisture from the bed, then ramped at 8 degrees Celsius per minute to a glass pool temperature of $1500{ }^{\circ} \mathrm{C}$. The material was held at $1500{ }^{\circ} \mathrm{C}$ for two hours prior to pour 
initiation. The pour for Run CIM 30-2 took approximately twice as long to initiate as the first cullet production run, CIM 30-1. The pour rate for CIM 30-2 was also much lower than CIM 30-1 and dripping began with approximately 1400 grams remaining in the melter. The pour was stopped after drips were 10 seconds apart, leaving a melter heel consisting of highly porous glass which filled the melter to within $1 / 2$ " of the top of the conical section, similar to CIM 30-1. A significant amount of entrainment was noted during the run, beginning when the bed temperature reached $155^{\circ} \mathrm{C}$, indicative of boric acid decomposition. Boron oxide was used to prepare the batch chemicals, but absorption of moisture from the atmosphere likely converted some of the material to boric acid while the batch awaited processing. HEPA differential pressure increased from 3.0 inwc to 3.3 inwc during the run.

Samples were taken of the cullet and melter heel from run CIM 30-1, while four pour samples were taken during CIM 30-2. The sample results indicated that the cullet produced was not uniform. The amount of silica in the cullet increased from $27 \mathrm{wt} \%$ at the start of the pour to $77 \mathrm{wt} \%$ in the melter heel. The amount of alumina, lanthanum oxide, and strontium oxide decreased by a factor of five from the start of the pour to the melter heel, while boron oxide concentration was relatively uniform. Therefore, the decision was made to combine the cullet from these two runs with 30SrABS cullet produced in the drain tube test stand (DTTS run 30-4) and remelt the batch in the 5" CIM using a bubbler to homogenize the glass. When the melter batch reached $1500^{\circ} \mathrm{C}$, argon was bubbled into the glass for approximately an hour and 40 minutes at flowrates ranging from 0.26 scfh to $1.0 \mathrm{scfh}$. The subsequent pour resulted in a constant pour rate from start to finish, indicative of uniform composition, and left only a very small heel in the melter. Sample analyses confirmed that the cullet produced from the remelt was uniform with a lanthanum content of 31 wt\%.

35SrABS cullet was also produced in CIM5 starting with batch chemicals and using a bubbler to ensure homogeneity. No processing problems were encountered.

\section{V.B.10. CIM5 Runs \#40 and \#41 - 49 wt\% Lanthanide Loaded 30SrABS Glass}

At the lower Ln loadings a rather large heel of high viscosity glass remained in the melter after a pour. To reduce the size of this glass heel a higher lanthanum content cullet, 30SrABS, was evaluated to increase the lanthanide content in the residual glass thereby decreasing the viscosity . 
CIM5 Runs \#40 and \#41 both produced a good glass product, each targeting the production of 2190 grams of $49 \mathrm{wt} \% \mathrm{Ln} 30 \mathrm{SrABS}$ glass. For each run, 1590 grams of 30SrABS cullet was charged to the CIM5 vessel followed by the addition of the oxalate precipitate slurry from the coupled precipitator. The automatic power control program was used to dry, calcine and vitrify the batches over the normal 6 hour 50 minute run cycle. After a 60 minute hold at peak temperature, glass pouring was initiated and samples captured to provide pour rate information. The coloration of the 30SrABS glass samples indicated a higher residual loading than is produced with $25 \mathrm{SrABS}$ glass runs. However, the variation in loading from start to finish was still prevalent as evidenced by the pour rate variations, although somewhat better than with $25 \mathrm{SrABS}$. All glass was poured from the vessel, leaving only a cold glass plug within the drain tube.

Unfortunately however, there was temperature evidence of a bed volume expansion between 1300 and $1450^{\circ} \mathrm{C}$. Additional evidence was provided by the observation that the CIM vessel interior walls were clean following the pour. It appears the softening point of the 30SrABS cullet results in too much overlap with the cerium redox temperature range.

\section{V.B.11.CIM5 Run \#42 - 49 wt\% Lanthanide Loaded 35SrABS Glass}

The first of two planned runs to produce $49 \mathrm{wt} \%$ Ln loaded 35SrABS glass was completed using the $35 \mathrm{SrABS}$ cullet. An extreme batch bed expansion was experienced with this run which forced a quantity of the foamy glass out of the top of the melter vessel. With the higher La loaded 35SrABS cullet, glass softening begins at a lower temperature, while cerium reduction is still evolving oxygen gas from within the batch bed. This gas cannot escape the sticky cullet, resulting in an expansion of the cullet bed. The potential for this type volume expansion was recognized prior to the run and appropriate preparations were made. To avoid over pressurization of the melter vessel, the crusty cap was manually penetrated to vent the expanding bed and power was applied to the drain tube to initiate glass pouring as quickly as possible.

The porous glass that exited the top of the CIM was very friable, and easily removed the following day after cooldown. There was no damage to equipment as a result of this expansion. Only $1 / 4$ " of foam remained in the conical bottom section of the CIM at the completion of pouring. No further testing of the $35 \mathrm{SrABS}$ cullet was pursued because of the severity of the bed volume expansion. 
WSRC-TR-99-0434

Page 28 of 59

\section{V.C. Bubbler Evaluation to Homogenize 49 Wt\% Ln Loaded 25SrABS Glass}

At the direction of the design authority five runs were conducted using argon bubbling during the final high temperature soak period to facilitate mixing within the glass pool. All five runs showed marked improvement in the homogenization of the final glass product as evidenced by the measured pour rates, the appearance of the pour samples collected and the analytical analyses. In each run 1258 grams of $25 \mathrm{SrABS}$ cullet were batched with the standard oxalate precipitate product from CP1 to produce a $49 \mathrm{wt} \% \mathrm{Ln}$ loaded $25 \mathrm{SrABS}$ glass. The thermal processing was controlled by the automatic power control program to dry, calcine and vitrify each batch over a 350 minute schedule. The length of time the glass was allowed to soak at temperature prior to initiation of argon bubbling, the length of time the bubbling was performed, and the length of the final soak after bubbling was completed to allow residual bubbles to escape the glass pool varied in each run.

The purpose of these runs was to bracket the acceptable bubbler operating region. Bubbling for 60 minutes at $1.0 \mathrm{scfh}$ appeared to produce an acceptable, homogeneous glass. However, bubbling at $1.0 \mathrm{scfh}$ for 15 minutes was insufficient to homogenize the glass. Bubbling times of 30 and 45 minutes appeared to be marginal.

\section{V.C.1. CIM5 Run \#43 - 49 wt\% Ln Loaded 25SrABS Glass with 60 Minutes Argon Bubbling}

Bubbling at 1.0 scfh was initiated at the beginning of the soak period and was continued for 60 minutes. The glass pool was then allowed to soak for an additional 20 minutes to permit the bubbles to escape. Visual inspection of the glass samples showed a very consistent coloration from the initial to the final sample. All samples were nearly free of entrapped bubbles. Figure 18 shows how the pour rate and Ln content varied during the glass pour. 
WSRC-TR-99-0434

Page 29 of 59

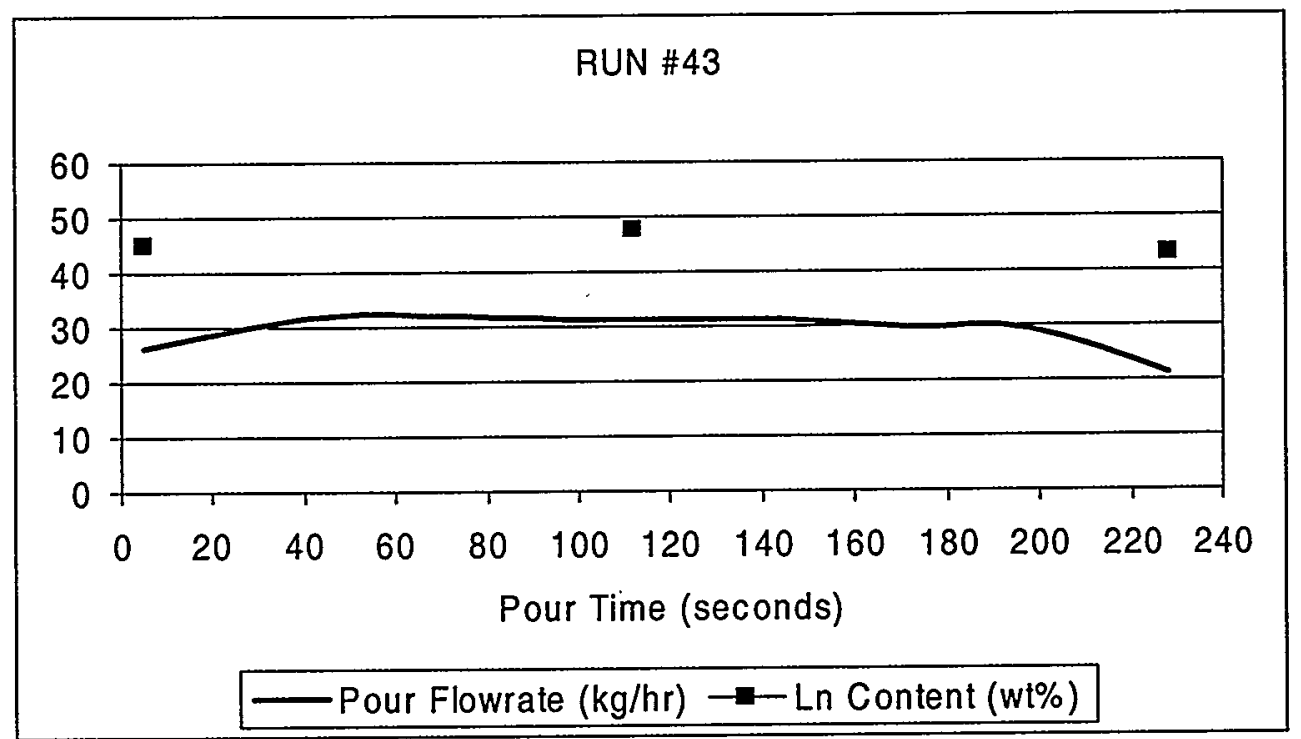

Figure 18

\section{V.C.2. CIM5 Run \#44 - 49 wt\% Lanthanide Loaded 25SrABS Glass with 30 Minutes Argon Bubbling}

Bubbling at $1.0 \mathrm{scfh}$ was initiated 10 minutes after the beginning of the soak period and was continued for 30 minutes. After conclusion of bubbling the glass pool soaked for an additional 20 minutes prior to initiating pouring: A high temperature interlock as a result of a higher than normal drain tube temperature shut down the system. Thirty six minutes were required to recover melter temperatures lost during the interlock shutdown. The glass pour stream stopped abruptly after 4 minutes 12 seconds of pouring, followed by only four drips before stopping. A check of the drain tube after cooling revealed the tube to be empty of glass except for the lowest 1 inch, containing the cold glass plug. Visual inspection of the glass samples showed a very consistent coloration from the initial to the final sample. All samples were nearly free of entrapped bubbles. A plot of pour rate is shown in Figure 19. 
WSRC-TR-99-0434

Page 30 of 59

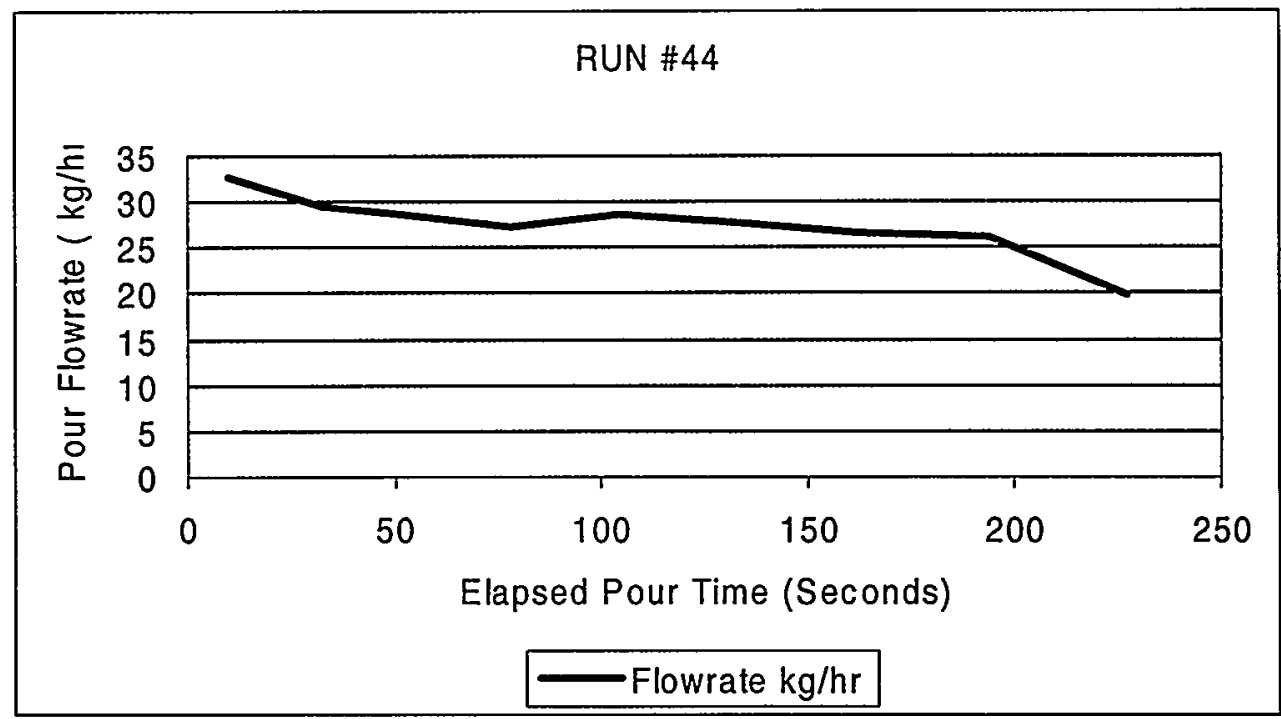

Figure 19

\section{V.C.3. CIM5 Run \#45 - 49 wt\% Lanthanide Loaded 25SrABS Glass with 15 Minutes Argon Bubbling}

Fifteen minutes after the beginning of the soak period bubbling was initiated at $1.0 \mathrm{scfh}$ for a duration of 15 minutes. After the conclusion of bubbling the glass pool soaked for an additional 15 minutes. The glass pour stream stopped abruptly after 4 minutes 6 seconds of pouring, followed by only four drips before stopping. The high initial pour rate and the subsequent marked decrease in pour rate indicated non-homogeneity in the glass being poured. Visual inspection of the glass samples revealed a higher loading at the beginning of the pour and a lower loading at the end. Figure 20 shows pour rate as a function of pour time. An 1/8" heel consisting of a lightly colored bubbly, glass remained in the bottom of the vessel. 


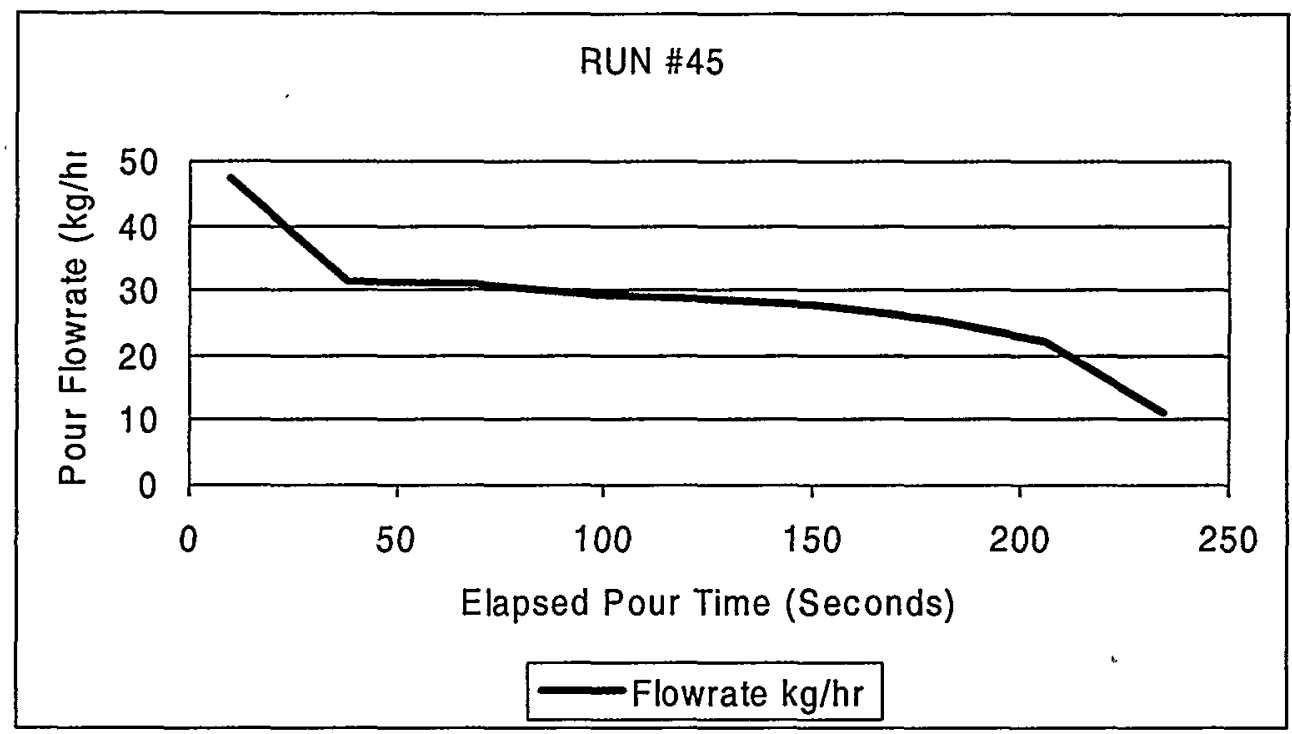

Figure 20

\section{V.C.4. CIM5 Run \#46 - 49 wt\% Lanthanide Loaded 25SrABS Glass with 30 Minutes Argon Bubbling}

The bubbler was operated for 30 minutes at 1.0 scfh beginning 10 minutes after the start of the soak period. Glass pouring was initiated 15 minutes after conclusion of bubbling. The glass pour stream stopped abruptly after 4 minutes 30 seconds of pouring, followed by only four drips before stopping. Visual inspection of the glass samples showed a very consistent coloration from the initial to the final sample. Glass pour rate is displayed in Figure 21. All samples were nearly free of entrapped bubbles.

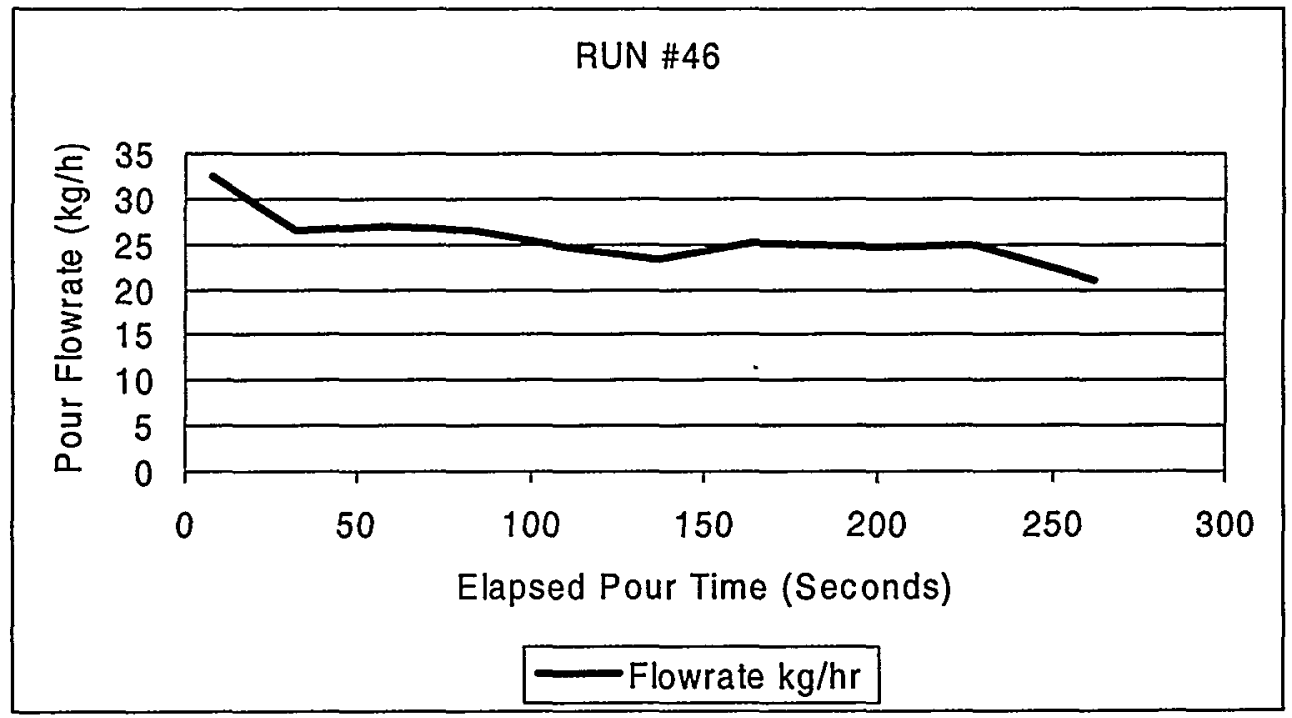

Figure 21 
WSRC-TR-99-0434

Page 32 of 59

\section{V.C.5. CIM5 Run \#47 - 49 wt\% Lanthanide Loaded 25SrABS Glass with 45 Minutes Argon Bubbling}

Bubbling was initiated immediately at the start of the soak period and continued for 45 minutes at 1.0 scfh. Glass pouring started 15 minutes after the conclusion of bubbling. The glass pour stream stopped abruptly after 4 minutes 12 seconds of pouring, followed by only four drips before stopping. Visual inspection of the glass samples showed a very consistent coloration from the initial to the final glass sample. Glass pour data results are depicted in Figure 22. All samples were nearly free of entrapped bubbles.

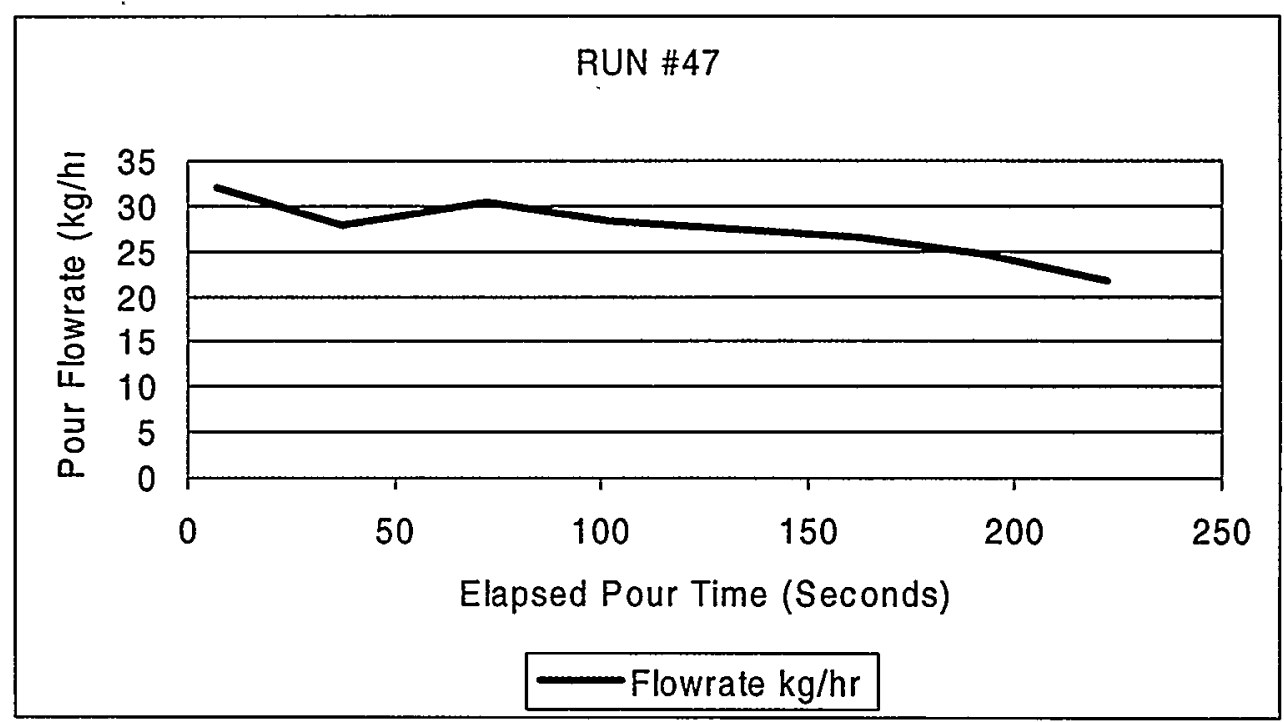

Figure 22

Based on the success of these five bubbler runs, the base process was changed to include the use of a bubbler in the production of a $49 \mathrm{wt} \% \mathrm{Ln}$ loaded $25 \mathrm{SrABS}$ glass. This method of operation was shown to produce a more homogeneous glass product that resulted in a more predictable and reproducible residual glass composition. The advantage is the reduced risk of a drain tube plug caused by exceeding the liquidus temperature of the highly loaded glass in the bottom of the melter ( 58 to $60 \mathrm{wt} \% \mathrm{Ln}$ ). Details of the five bubbler runs are provided in the run summaries that follow for Runs \#43 through \#48. 
WSRC-TR-99-0434

Page 33 of 59

\section{V.D. Evaluation of Process Extreme Conditions with Am/Cm Base Process - 49 wt\% Ln 25SrABS Glass}

With the base process specified, the next step in the development program evaluated the $49 \mathrm{wt} \% \mathrm{Ln}$ base process over several processing extremes. The conditions chosen for evaluation were the recovery from an interlock condition during the vitrification phase and increased cerium concentrations that would simulate the potential thermal reduction of americium and/or curium. These test were completed in CIM5 Runs \#48 through \#60.

Recovery from the high temperature interlock went smoothly and presented no processing problems. However, increased cerium concentrations in the $49 \mathrm{wt} \% \mathrm{Ln}$ SrABS glass resulted in significant volume expansions that presented serious processing problems. Several options for controlling the bed volume expansion were identified:

- Using $49 \mathrm{wt} \% \mathrm{Ln}$ glass, begin argon bubbling earlier in the run to facilitate venting of the oxygen that causes the bed volume expansion.

- Incorporate a power ramp hold point at $1180-1200^{\circ} \mathrm{C}$ to permit the bed and wall temperatures to equilibrate with the intent of allowing more of the oxygen to escape the bed before the cullet begins to soften and become sticky.

- Increase initial lanthanide loading from 49 to $58 \mathrm{wt} \%$. At the soak temperature (1400 to $1450^{\circ} \mathrm{C}$ ) add sufficient $25 \mathrm{SrABS}$ cullet to reduce lanthanide loading to $49 \mathrm{wt} \%$ and use the bubbler to homogenize the melt. Previous experience showed that high lanthanide loadings mitigated volume expansion problems.

Evaluations of the power ramp hold point and introduction of the bubbler at a lower temperature were unsuccessful in mitigating the volume expansions. Details of these evaluations are included under the Run \#54 and Run \#53 headings. Implementation of the third option, which started with a $58 \mathrm{wt} \% \mathrm{Ln}$ concentration and later diluted to $49 \mathrm{wt} \% \mathrm{Ln}$, resulted in a workable process.

The initial charge of cullet added to the melter was sufficient to produce a $58 \mathrm{wt} \%$ Ln loaded glass. The CIM5 base process was then used to dry, calcine and vitrify the glass. At the beginning of the normal soak period $\left(\sim 1400^{\circ} \mathrm{C}\right)$ the bubbler was inserted and an additional amount of cullet was added to attain a $49 \mathrm{wt} \% \mathrm{Ln}$ loaded final glass. The bubbler time was extended to 90 minutes due to the large heat loss caused by the cullet addition and the drain tube was energized earlier than planned to provide extra heat to reduce the glass viscosity and promote better mixing. Approximately 30 grams of $49 \mathrm{SrABS}$ cullet ( $49 \mathrm{wt} \%$ lanthanum) was added to the melter after pouring was terminated to seal the top of the drain tube and significantly reduce the risk of drain tube pluggage. Volume expansion was minimal with this processing mode and a homogeneous glass was produced as 
evidenced by the relatively consistent pour rate measured throughout the duration of the glass pours:

\section{V.D.1. CIM5 Run \#48 - 49 wt\% Ln 25SrABS Glass With High Temperature Interlock}

As in previous runs, 1258 grams of $25 \mathrm{SrABS}$ cullet were batched with the standard oxalate precipitate product from CP1 to produce a $49 \mathrm{wt} \% \mathrm{Ln}$ loaded 25SrABS glass. The thermal processing was controlled by the automatic power control sequence to dry, calcine and vitrify each batch over a 350 minute schedule. Bubbling was initiated at the beginning of the soak period and was continued for 45 minutes at $1.0 \mathrm{scfh}$. The glass pool was allowed to soak an additional 15 minutes after completion of bubbling. When pouring was initiated a hard wired interlock (optical pyrometer drain tube temperature) occurred. The control system was reset and the automatic power control sequence was used to restore the power outputs to the vessel, cone, and drain tube. Temperatures were about 100 ${ }^{\circ} \mathrm{C}$ below the normal value in the absence of an interlock. The air to the drain tube was left off and pouring resumed approximately one minute after power was reestablished. The pour rate started at $12 \mathrm{~kg} / \mathrm{hr}$ and increased to about $16 \mathrm{~kg} / \mathrm{hr}$ at the end of the pour as the glass temperature increased. Only a very small amount of glass remained in the cone of the melter after pouring was completed. Uniform composition over the pour period was evident based on visual observation of the sample color.

\section{V.D.2. CIM5 Run \#49 - 49 wt\% Ln 25SrABS Glass With 1.87X Cerium}

The CIM5 base process was used to dry, calcine and vitrify a $49 \mathrm{wt} \% \mathrm{Ln}$ loaded 25SrABS glass that contained 1.87 times the normal amount of cerium. The additional cerium, 'which replaced erbium (stand in for Am and $\mathrm{Cm}$ ), was used to permit evaluation of the process impact if both Am and $\mathrm{C}$ m were thermally reduced. Seven minutes prior to beginning the high temperature soak conditions (when argon bubbling was initiated), a severe bed expansion forced foamy cullet out the top of the CIM5 vessel, moving the top insulation cover board out of position. The foamy material quickly hardened when exposed to the ambient air above the vessel, resulting in pressurization of the CIM vessel as oxygen continued to be given off by the batch material. Attempts to vent the glass cap and vessel were unsuccessful as the vent paths were almost immediately closed with newly generated foam. Therefore, to relieve pressure buildup within the vessel that could potentially damage the vessel and induction coil, it was decided to initiate glass pouring. Approximately 260 grams of glass and crystalline material dripped from the drain tube before it became plugged. 
WSRC-TR-99-0434

Page 35 of 59

Attempts to reinitiate glass pouring were unsuccessful. The run was terminated and the batch was allowed to solidify within the vessel.

\section{V.D.3. CIM5 Run To Recover From Drain Tube Pluggage}

Attempts to free the drain tube of the crystallized material by drilling were unsuccessful. A 3/4" length of drain tube was removed but the newly exposed drain tube tip still contained crystalline material. X-ray analysis

i of the drain tube indicated a $3 / 4$ " plug in the tip end with the upper 2 " also filled with an unknown substance. The tip plug was subsequently removed by drilling. An attempt was then made to melt the contents of the vessel and drain tube by adding quantities of 50SrABS Hybrid and 25SrABS cullet, bubbling to homogenize the mixture, and then pouring to clear the vessel and drain tube. The melter vessel and conical bottom area were quickly heated by applying power to the respective induction coils. When the CIM vessel reached $1400{ }^{\circ} \mathrm{C}, 400$ grams of $50 \mathrm{SrABS}$ Hybrid cullet was added to the melter and allowed to melt and then 300 grams of 25SrABS cullet was added. Argon was bubbled through the glass pool at 1.0 scfh to mix the glass. When power to the drain tube induction coil was increased in preparation for pouring, a thermocouple contacting the induction coil and drain tube caused the power supply to fault. After several occurrences, the cause of the fault was discovered and corrected, allowing the glass to be successfully poured from the melter. When pouring was completed, 30 grams of 50SrABS cullet was added to the $\mathrm{CIM}$ and allowed to melt to provide a drain tube plug of known composition.

\section{V.D.4. CIM5 Run \#51 - 49 wt\% Ln 25SrABS Glass ,With 1.87X Cerium}

Run \#49, which produced the severe volume expansion, was repeated to gather additional information. The CIM5 base process was again used to dry, calcine and vitrify a $49 \mathrm{wt} \% \mathrm{Ln} 25 \mathrm{SrABS}$ glass that contained 1.87 times the normal amount of cerium. The oxalate precipitate for this run was prepared from a new surrogate feed batch and therefore, was different than that used previously in Run \#49. This run also produced a bed expansion just prior to reaching the high temperature bubbling and soak period. The volume expansion was kept within the confines of the vessel this time however, by frequently venting the cap. Forty five additional minutes (beyond the standard run schedule) were required before the argon bubbler could be inserted and the soak period initiated. After bubbling for 55 minutes and allowing 10 minutes for bubble dissipation, pouring was initiated. The steady decrease in the measured pour rate indicated the glass was still not homogeneous after 55 minutes of 
WSRC-TR-99-0434

Page 36 of 59

bubbling, being more heavily loaded initially. At the conclusion of the pour, 70 grams of 50SrABS cullet was melted and drained to flush the drain tube. Tip cooling air was applied to the drain tube, then an additional 50 grams of 50SrABS cullet was melted to fill the drain tube and provide a cold glass plug.

\section{V.D.5. CIM5 Run \#52 - 58 wt\% Ln 25SrABS Glass With 1.87X Cerium}

Run \#52 was performed to gather additional information in defining a base process to mitigate the severe volume expansions that occur when processing oxalate precipitate batches containing higher cerium content. The targeted Ln loading for this run was increased from the standard 49 wt\% to $58 \mathrm{wt} \%$, which in effect reduced the quantity of cullet in the initial batch by about $40 \%$. It appears that the quantity of cullet has a direct effect on the severity of the volume expansion. The CIM5 base process was again used to dry, calcine and vitrify the $58 \mathrm{wt} \%$ Ln loaded $25 \mathrm{SrABS}$ glass. The oxalate precipitate for this run was prepared from the new surrogate feed batch that was used previously in Run \#51. This run produced a bed expansion' just prior to reaching the high temperature bubbling and soak period, but it only'rose half way up the melter vessel wall remaining within the confines of the vessel. After bubbling for 60 minutes and allowing 10 minutes for bubble dissipation, pouring was initiated. The glass dripped from the drain tube for 4 minutes before a stream was achieved. The slow pour initiation appears to be caused by flushing the drain tube with 50SrABS which leaves a foamy glass resulting from reduction of the cerium in the 50SrABS cullet inside the drain tube. The measured pour rate while streaming was $40-45 \mathrm{~kg} / \mathrm{hr}$. The pour behavior indicated that the batch was still not completely homogeneous after 60 minutes of bubbling. At the conclusion of the pour, 50 grams of $50 \mathrm{SrABS}$ cullet was melted and drained to flush the drain tube and avoid subsequent liquidus problems. This too, dripped from the drain tube never'reaching a streaming condition. Tip cooling air was applied to the drain tube and then an additional 30 grams of 50SrABS cullet was added to provide a cold glass plug seal over the drain tube.

\section{V.D.6 CIM5 Run \#53 - 49 wt\% Ln 25SrABS Glass With 1.87X Cerium - Early Bubbler Installation to Facilitate Venting}

In Run \#53 the bubbler was introduced at a lower temperature in an attempt to break up the foamy expansion and facilitate oxygen venting. The standard 49 wt $\%$ Ln loading was targeted for this run and the CIM5 base process was again used to dry, calcine and vitrify the batch. With the batch bed centerline temperature at $1180-1200{ }^{\circ} \mathrm{C}$, the bubbler was 
WSRC-TR-99-0434

Page 37 of 59

inserted into the powdered oxide bed and argon introduced at $1.5 \mathrm{scfh}$. As the cullet began to soften in its transition to molten glass, the bubbles from the bubbler tube were observed to rise to and break through the surface, providing a vent path for the cerium reduction product to escape the batch bed. A volume expansion did occur prior to reaching the soak temperature, rising to an elevation approximately 2 inches below the top insulating cover over the CIM vessel. The bed expansion eventually lifted the cover over the vessel about 4 minutes into the 60-minute soak period. After bubbling for 60 minutes and allowing 10 minutes for bubble dissipation, pouring was initiated. - A steady glass stream was achieved immediately upon pour initiation, ranging from 26 to $28 \mathrm{~kg} / \mathrm{hr}$ pour rate. At the conclusion of pouring, tip cooling air was applied to the drain tube and then 30 grams of 50SrABS cullet was added to provide a glass plug seal over the drain tube.

\section{V.D.7. CIM5 Run $\$ 54$ - 49 wt\% Ln 25SrABS Glass With 1.87X Cerium - Hold Point to Equilibrate, Temperatures and Promote Venting}

A 49 wt\% Ln loading was targeted for this run and the CIM5 base process was used to dry, calcine and vitrify the batch. The automatic power control sequence program was paused when the bed temperature reached $1180^{\circ} \mathrm{C}$ in an attempt to allow time for the oxygen being given off by the cerium reduction within the batch bed to vent. With the batch bed centerline temperature at $1180-1200{ }^{\circ} \mathrm{C}$, the power input was held steady for 90 minutes. Bed temperatures continued to rise however, due to thermal inertia and leveled off in the 1350 to $1450^{\circ} \mathrm{C}$ range. As the cullet began to soften in its transition to molten glass, the foam produced was observed to rise as the cerium reduction product pushed upward to escape the batch bed. The bed expansion did eventually lift the cover over the vessel 54 minutes into the power hold period: After the glass was mixed by argon bubbling for 60 minutes and allowing 10 minutes for bubble dissipation, pouring was initiated. A steady pour stream was achieved upon pour initiation with measured pour rates ranging from 21 to $23.7 \mathrm{~kg} / \mathrm{hr}$. Tip cooling air was applied to the drain tube and then 30 grams of $49 \mathrm{SrABS}$ (49 wt\% lanthanum and cerium free) cullet was added to fill the drain tube and provide a glass plug seal.

\section{V.D.8. CIM5 Run \#55 - 55 wt\% Ln 25SrABS Glass With 1.87X Cerium}

Run \#55 was performed to gather additional information in determining a base process to mitigate the severe volume expansions that occur when processing oxalate precipitate batches containing higher cerium content. The targeted $55 \mathrm{wt} \%$ Ln loading for this run was between the standard 49 
WSRC-TR-99-0434

Page 38 of 59

wt\% loading that produced unacceptable bed expansions and the higher $58 \mathrm{wt} \%$ that resulted in a controlled bed expansion. The CIM5 base process was again used to dry, calcine and vitrify a $55 \mathrm{wt} \% \mathrm{Ln} 25 \mathrm{SrABS}$ glass that contained 1.87 times the normal amount of cerium. The oxalate precipitate for this run was from the new surrogate feed batch that used previously in Runs \#51 - \#54. A bed expansion that produced extending to within ' 3 " of contacting 'the top insulating cover was evident at the initiation of the high temperature bubbling and soak period. Thirteen minutes later when the drain tube power reached peak output, the foam rose to contact the top insulating cover board and had to be manually vented and pushed back into the confines of the melter vessel. A 60 minute delay in initiating actual argon flow to the bubbler may have contributed to difficulty in completely emptying the drain tube upon melter draining. After soaking at peak power for 60 minutes, then soaking for an additional 70 minutes (bubbling for 60 minutes and allowing 10 minutes for bubble dissipation), pouring was initiated. The glass poured from the drain tube for 2 minutes and 40 seconds before dripping and stopping. The measured pour rate while streaming was $45-34 \mathrm{~kg} / \mathrm{hr}$. The decreasing pour rate indicated the glass was not homogeneous after 60 minutes of bubbling, being more heavily loaded initially. At the conclusion of the pour (before application of drain tube cooling air), 100 grams of 49SrABS cullet was added to' flush the drain tube and avoid subsequent liquidus problems. This glass, however, did not pour. An additional $100^{\circ}$ grams of $49 \mathrm{SrABS}$ cullet was added to the melter to provide additional head but again, pouring was unsuccessful. Probing the lower end of the drain tube revealed what appeared to be a hard nonvitreous material plugging the end of the drain tube. Tip cooling air was applied to the drain tube and then the power was ramped down to shut down the CIM.

\section{V.D.9. CIM5 Run Plan SRT-ÄMC-99-186 To Recover, From Drain Tube Pluggage}

This run was performed to flush the drain tube with a known glass composition following the mechanical removal of a crystalline plug in the lower $1 / 2$ " of the drain tube. The archived cullet from CIM5 Run \#47, a standard $49 \mathrm{wt} \% \mathrm{Ln}$ loaded glass, was remelted in this run. An accelerated heating process was incorporated to vitrify the $49 \mathrm{wt} \% \mathrm{Ln} 25 \mathrm{SrABS}$ glass. Argon bubbling was initiated with the bubbler tube located $1 / 2$ " above the bottom of the melter vessel, and continued for 60 minutes at $1.5 \mathrm{scfh}$. After bubbling for 60 minutes at the peak power input and allowing 10 minutes for bubble dissipation, pouring was attempted. Additional power application to the drain tube was required to initiate pouring. Within two minutes, a stream was achieved. The measured pour rate while streaming 
WSRC-TR-99-0434

Page 39 of 59

was $21 \mathrm{~kg} / \mathrm{hr}$. Tip cooling air was applied to the drain tube and then 30 grams of 49SrABS cullet was melted to fill the drain tube and provide a cold glass plug.

\section{V.E. CIM5 Process Development for High Cerium Feed}

The next three runs were configured such that the initial batch of washed oxalate slurry containing 1.87 times the normal amount of cerium and glass formers yielded a $58 \mathrm{wt} \% \mathrm{Ln}$ loading (a loading that consistently produces minimum bed expansion). Once the nominal glass temperature was reached $\left(\sim 1450^{\circ} \mathrm{C}\right)$ and agitation of the melt was initiated with the argon bubbler, additional glass former (cullet or glass beads) was added to the melt to target a lanthanide loading of 49 wt\% in the final glass product. Volume expansion was minimal in all three 58 wt\% runs and a homogeneous glass was produced as evidenced by the relatively consistent pour rate measured throughout the duration of each glass pour.

\section{V.E.1 CIM5 Run \#56 - 49 wt\% Ln 25SrABS Glass with 1.87X Cerium and Late Cullet Addition}

Run \#56 was an attempt to reduce the volume expansion caused by the reduction of cerium in the oxalate precipitate by making two additions of cullet to reduce the amount of viscous material covering the top surface of the melter during the cerium reduction phase. An initial charge of cullet (753.1 grams) to yield a $58 \mathrm{wt} \%$ glass was added to the melter followed by the oxalate precipitate from run CP766. The CIM5 base process was used to dry, calcine and vitrify the glass. At the beginning of the normal soak period the bubbler was inserted with a flow of 1.5 scfh argon. An additional 505.3 grams of cullet was added to attain a $49 \mathrm{wt} \%$ loaded final glass. The bubbler time was extended to 90 minutes due to the large heat loss caused by the cullet addition. The drain tube was energized earlier than planned to provide extra heat to reduce the glass viscosity and promote better mixing. When pouring was initiated the measured rate started at $27 \mathrm{~kg} / \mathrm{hr}$ and ended at $22 \mathrm{~kg} / \mathrm{hr}$. An additional 30 grams of 49SrABS cullet was added to the melter after pouring was terminated to seal the top of the drain tube.

\section{V.E.2. CIM5 Run \#57 - 49 wt\% Ln 25SrABS Glass with 1.87X Cerium and Late Marble Addition}

Run \#57 used two late marble additions instead of the one cullet addition performed in Run \#56. This mode was evaluated in an attempt to reduce the temperature drop and possibly promote better mixing by maintaining 
lower viscosity. An initial charge of cullet (753.1 grams) was added to the melter followed by the oxalate precipitate from CP767. The standard program was used to dry, calcine and vitrify the glass. Additional power was required to obtain the temperatures called for in the run plan $\left(1450^{\circ} \mathrm{C}\right.$ on the vessel and $1430^{\circ} \mathrm{C}$ in the glass) so the insertion of the bubbler was delayed. A 250 gram charge of $3 / 8$ " $25 \mathrm{SrABS}$ marbles was added at the same time as the bubbler. Forty three minutes later a second 255 gram charge of marbles was added. During the next 60 minutes of bubbling a bubbler pressure of approximately 9 inwc was measured with a newly installed transmitter. A glass stream was achieved within 27 seconds of the pour sequence initiation. Measured pour rates of 38 to $31 \mathrm{~kg} / \mathrm{hr}$ were obtained. A 30 gram addition of $49 \mathrm{SrABS}$ cullet was made after the pour sequence.

\section{V.E.3. CIM Run \#58 - 49 wt\% Ln 25SrABS Glass with 1.87X Cerium, Late Marble Addition, and Modified Power Application}

Run \#58 was similar to Run \#57 except the automatic program was modified to apply additional power for the vitrification phase. Additional power was applied earlier in the run to obtain desired temperatures based on the experience from Run \#57. The same cullet/marble additions were made as in Run \#57. Slightly elevated temperatures were obtained due to the increased power, but they were well within the operating range and tended to promote better mixing. A bubbler pressure of $\sim 7.5$ inwc was obtained. A glass stream was obtained within 34 seconds of the pour sequence initiation. Measured pour rates of 40 to $31 \mathrm{~kg} / \mathrm{hr}$ were obtained. A 30 gram addition of $49 \mathrm{SrABS}$ was made after the pour sequence to provide a cold glass plug.

\section{V.F. Evaluation of Am/Cm Base Process Extreme Conditions}

Two CIM5 runs evaluating base proces's extremes were completed. The first run (\#59) targeted a $49 \mathrm{wt} \%$ Ln loaded $25 \mathrm{SrABS}$ glass from an oxalate precipitate batch containing $1.87 \mathrm{X}$ times the normal amount of cerium. High initial loading followed by late $25 \mathrm{SrABS}$ marble addition was used to obtain the desired loading. A planned interlock was imposed to test the system response. The second run (\#60) was a standard 49 wt\% glass with normal cerium content. An interlock was introduced during the bubbling phase of the run to evaluate system response. 
WSRC-TR-99-0434

Page 41 of 59

\section{V.F.1. Run \#59 -49 wt\% Ln 25SrABS Glass, with 1.87X Cerium, Late Cullet Addition, and Interlock}

Run \#59 was batched to produce a $58 \mathrm{wt} \%$ glass and used two late marble additions that had proven successful in previous runs to dilute to the 49 wt\% target Ln loading. As in the earlier runs, the volume expansion at the $58 \mathrm{wt} \%$ loading was minimized. The automatic program was used to bring the melter back to temperature after each 250 gram marble addition was made. During the bubbling period after the second marble addition, the system was interlocked by pressing the E-Stop button. All power was removed and temperatures began rapidly dropping. When the control thermocouple reached $1250^{\circ} \mathrm{C}$, power was reapplied to the system at the same levels as before the interlock. The melter was without power for approximately three minutes. After the temperatures recovered, the pour sequence was initiated. A stream was obtained within 35 seconds. Pour rates started at $33 \mathrm{~kg} / \mathrm{hr}$ and ended at $28 \mathrm{~kg} / \mathrm{hr}$. An additional 30 grams of 49SrABS cullet was added after the cooldown sequence was activated to seal the top of the drain tube.

\section{V.F.2. Run \#60 - 49 wt\% Ln 25SrABS Glass with Stãndard Power Application, Bubbler, and Interlock}

Run \#60 used a standard batch of precipitate with normal cerium content to evaluate the reaction to an interlock during bubbling. The oxalate was hand fed into the melter instead of using the coupled system. When the melter was in the soaking/bubbling stage, an interlock was initiated. After TID temperature cooled to $\sim 1250{ }^{\circ} \mathrm{C}$, the power was reapplied. Approximately 3 minutes were required for the indicated temperature loss. Pour was initiated after temperatures recovered and a stream was observed within 24 seconds. Pour rates started at $33 \mathrm{~kg} / \mathrm{hr}$ and ended at $25 \mathrm{~kg} / \mathrm{hr}$. Thirty grams of $49 \mathrm{SrABS}$ were added to the melter after the pour was completed to seal the drain tube.

\section{REFERENCES}

1. Americium-Curium Stabilization - 5" Cylindrical Induction Melter System Design Basis (U), SRT-AMC-99-0001, Rev. 0, January 15,1999.

2. D. C. Witt, CIM5 Experimental Run Forecast (U), SRT-AMC-99-0004, January 7, 1999.

3. D. C. Witt, et.al, CIM5 Operational Tests Results (U), SRT-AMC-99-0058, March 15, 1999. 
WSRC-TR-99-0434

Page 42 of 59

4. T. M. Jones, CIM5 Phase III:Automated Standard Power Application (U), SRTAMC-99-0047, February 24, 1999.

5. WSRC-NB-98-00226;5” Cylindrical Induction Melter Development Laboratory Notebook

6. : WSRC-NB-98-00227, 5" Cylindrical-Induction Melter Development

$\because \quad$ Laboratory Notebook i

7. WSRC-NB-98-00271, Coupled Precipitator One Laboratory Notebook

8. WSRC-NB-99-00135, Coupled Precipitator One Laboratory Notebook

9. WSRC-NB-99-00109, Coupled Precipitator Two and Scoping Lab-Scale Test Laboratory Notebook

10. D. C. Witt, CIM5 Loading Calculations (U) SRT-AMC-99-0038, February 11,1999 .

11. T. M. Jones and D. C. Witt, CIM5 Phase III -Run \#15 - 58 wt\% Ln 25SrABS From CP-732, SRT-AMC-99-0056, March 1,1999.

12. T. M. Jones and D. C. Witt, CIM5 Phase III -Run \#16 - 58 wt \% Ln 25SrABS (2X Cerium) From CP-733, SRT-AMC-99-0057, March 6,1999.

13. T. M. Jones and D. C. Witt, CIM5 Phase III -Run \#17 - 58 wt\% Ln 25SrABS From CP-734, SRT-AMC-99-0059, March 8,1999.

14. T. M. Jones and D. C. Witt, CIM5 Phase III -Run \#18 - 58 wt\% Ln 25SrABS From CP-735, SRT-AMC-99-0060, March 10,1999.

15. T. M. Jones and D. C. Witt, CIM5 Phase III -Run \#19-58 wt\% Ln 25SrABS (2X Cerium) From CP-736, SRT-AMC-99-0062, March 15,1999.

16. T. M. Jones and D. C. Witt, CIM5 Phase III -Run \#20 - 58 wt\% Ln 25SrABS (1.7X Cerium) From CP-737, SRT-AMC-99-0064, March 22,1999.

17. T. M. Jones and D. C. Witt, CIM5 Phase III -Run \#21 - 58 wt \% Ln 25SrABS (1.87X Cerium) From CP-738, SRT-AMC-99-0071, March 24,1999.

18. T. M. Jones and D. C. Witt, CIM5 Job Plan To Thermally Shock Drain Tube To Remove Plug, SRT-AMC-99-0074, April 5,1999. 
WSRC-TR-99-0434

Page 43 of 59

19. T. M. Jones and D. C. Witt, CIM5 Job Plan To Recover From Drain Tube Pluggage, SRT-AMC-99-0083, April 20,1999.

20. T. M. Jones and D. C. Witt, CIM5 Phase III -Run \#22-58 wt\% Ln 25SrABS From 1/4" Marbles And CP-740, SRT-AMC-99-0086, April 22,1999.

21. T. M. Jones and D. C. Witt, CIM5 Job Plan To Recover From Drain Tube Pluggage, SRT-AMC -99-0088, April 28,1999.

22. T. M: Jones and D. C. Witt, CIM5 Job Plan To Replace Drain Tube Plug With 30SrABS Glass, SRT-AMC-99-0093, May 4,1999.

23. T. M. Jones and D. C. Witt, CIM5 Phase III -Run \#23 - 58 wt\% Ln 25SrABS From CP2-1, SRT-AMC-99-0094, May 4,1999.

24. T. M. Jones and D. C. Witt, CIM5 Phase III -Run \#24-58 wt\% Ln 25SrABS From CP2-2, SRT-AMC-99-0097, May 6,1999.

25. T. M. Jones and D. C. Witt, CIM5 Phase III -Run \#25 - 58 wt\% Ln 25SrABS From CP-741, SRT-AMC-99-0098, May 11,1999.

26. T. M. Jones and D. C. Witt, CIM5 Phase III -Run \#26 - 58 wt\% Ln 25SrABS From CP2-3, SRT-AMC-99-0102, May 12,1999.

27. T. M. Jones and D. C. Witt, CIM5 Phase III -Run \#27 - 58 wt\% Ln 25SrABS From CP2-4, SRT-AMC-99-0105, May 14,1999.

28. T. M. Jones and D. C. Witt, CIM5 Phase III -Run \#28-47 wt\% Ln 25SrABS From CP-742, SRT-AMC-99-0107, May 18,1999.

29. T. M. Jones and D. C. Witt, CIM5 Phase III -Run \#29 - 47 wt\% Ln 25SrABS From CP2-5, SRT-AMC-99-0109, May 20,1999.

30. T. M. Jones and D. C. Witt, CIM5 Phase III -Run \#30 - 52 wt\% Ln 25SrABS From CP2-6, SRT-AMC-99-0112, May 20,1999.

31. T. M. Jones and D. C. Witt, CIM5 Phase III -Run \#31 - 52 wt\% Ln 25SrABS From CP2-7, SRT-AMC-99-0113, May 24,1999.

32. T. M. Jones and D. C. Witt, CIM5 Phase III -Run \#32 - 55 wt\% Ln 25SrABS From CP-743, SRT-AMC-99-0114, May 25,1999.

33. T. M. Jones and D. C. Witt, CIM5 Phase III -Run \#33 - 55 wt\% Ln 25SrABS From CP-744, SRT-AMC-99-0117, May 26,1999. 
WSRC-TR-99-0434

Page 44 of 59

34. T. M. Jones and D. C. Witt, CIM5 Phase III -Run \#34 - 50 wt\% Ln 25SrABS From CP-745, SRT-AMC-99-0118, June 1,1999.

35. T. M. Jones and D. C. Witt, CIM5 Phase III -Run \#35 - 50 wt\% Ln 25SrABS From CP2-8, SRT-AMC-99-0121, June 2,1999.

36. T. M. Jones and D. C. Witt, CIM5 Phase III -Run \#36 - 49 wt\% Ln 25SrABS From CP-746 with High Temp ILK, SRT-AMC-99-0122, June 7,1999.

37. T. M. Jones and D. C. Witt, CIM5 Phase III -Run \#37 - 49 wt\% Ln 25SrABS From CP-747 with High Temp ILK;'SRT-AMC-99-0123, June 8,1999.

38. T. M. Jones and D. C. Witt, CIM5 Phase III -Run \#38 - 49 wt\% Ln 25SrABS From CP-748 with 1/4" Marbles, SRT-AMC-99-0125, June 9,1999.

39. T. M. Jones and D. C. Witt, CIM5 Phase III -Run \#39-49 wt\% Ln 25SrABS From CP-749 with 1/4" Marbles, SRT-AMC-99-0126, June 10,1999.

40. T. M. Jones and D. C. Witt, CIM5 Job Plan to Flush CIM With 30SrABS Glass from Batch Chemicals, SRT-AMC-99-0129, June 18,1999.

41. T. M. Jones and D. C. Witt, CIM5 Job Plan to Produce 30SrABS Cullet from Batch Chemicals, SRT-AMC-99-0130; June 21,1999.

42. T. M. Jones and D. C. Witt, CIM5 Job Plan to Re-Melt and Mix 30SrABS Cullet, SRT-AMC-99-0137, June 29,1999.

43. T. M. Jones and D. C. Witt, CIM5 Job Plan to Produce 35SrABS Cullet from Batch Chemicals, SRT-AMC-99-0140, July 6,1999.

44. T. M. Jones and D. C. Witt, CIM5 Phase III -Run \#40 - 49 wt\% Ln 30SrABS From CP-750, SRT-AMC-99-0141, July 13,1999.

45. T. M. Jones and D. C. Witt, CIM5 Phase III -Run \#41-49 wt\% Ln 30SrABS From CP-751, SRT-AMC-99-0142, July 14,1999.

46. T. M. Jones and D. C. Witt, CIM5 Phase III -Run \#42 - 49 wt\% Ln 35SrABS From CP-752, SRT-AMC-99-0143, July' 15,1999.

47. T. M. Jones and D. C. Witt, CIM5 Phase III -Run.\#43 - 49 wt\% Ln 25SrABS From CP-753 With Auto Standard Power and Bubbled To Mix, SRT-AMC-990144 , July 21,1999 . 
WSRC-TR-99-0434

Page 45 of 59

48. T.M. Jones and D. C. Witt, CIM5 Phase III -Run \#44-49 wt\% Ln 25SrABS From CP-754 With Auto Standard Power and Bubbled To Mix, SRT-AMC-990149, July 22,1999.

49. T. M. Jones and D. C. Witt, CIM5 Phase III -Run \#45 - 49 wt\%. Ln 25SrABS From CP-755 With Auto Standard Power and Bubbled To Mix, SRT-AMC-990151, July 26,1999.

50. T. M. Jones and D. C. Witt, CIM5 Phase III -Run \#46-49 wt\% Ln 25SrABS From CP-756 With Auto Standard Power and Bubbled To Mix, SRT-AMC-990152 , July 27,1999 .

51. T.M. Jones and D. C. Witt, CIM5 Phase III -Run \#47 - 49 wt\% Ln 25SrABS From CP-757 With Auto Standard Power and Bubbled To Mix, SRT-AMC-990153 , July 28,1999 .

52. T. M. Jones and D. C. Witt, CIM5 Phase III -Run \#48 - 49 wt\% Ln 25SrABS From CP-758 With Auto Standard Power and Bubbled To Mix, SRT-AMC-990159, August 10,1999.

53. . T. M. Jones and D. C. Witt, CIM5 Phase III -Run \#49 - 49 wt\% Ln 25SrABS (1.87X Cerium/No Erbium) From CP-759 With Auto Standard Power and Bubbled To Mix, SRT-AMC-99-0161, August 11,1999.

54. T. M. Jones and D. C. Witt, CIM5 Phase III -Run \#50 - 49 wt \% Ln 25SrABS From CP-760 With Forced Hi Temp Interlock and Bubbled To Mix, SRTAMC-99-0164, August 12,1999.

55. T. M. Jones and D. C. Witt, CIM5 Job Plan To Recover From Drain Tube Pluggage, SRT-AMC-99-0165, August 17,1999.

56. T. M. Jones and D. C. Witt, CIM5 Phase III -Run \#51 - 49 wt\% Ln 25SrABS (1.87X Cerium/No Erbium) From CP-761 With Auto Standard Power and Bubbled To Mix, SRT-AMC-99-0172, August 23,1999.

57. T. M. Jones and D. C. Witt, CIM5 Phase III -Run \#52 - 58 wt\% Ln 25SrABS (1.87X Cerium/No Erbium) From CP-762 With Auto Standard Power and Bubbled To Mix, SRT-AMC-99-0173, August 25,1999.

58. T. M. Jones and D. C. Witt, CIM5 Phase III -Run \#53 - 49 wt \% Ln 25SrABS (1.87X Cerium/No Erbium) From CP-763 With Auto Standard Power and Earlier Bubbler To Mix, SRT-AMC-99-0177, August 26,1999. 
WSRC-TR-99-0434

Page 46 of 59

59. T. M. Jones and D. C. Witt, CIM5 Phase III -Run \#54-49 wt\% Ln 25SrABS (1.87X Cerium/No Erbium) From CP-764 With Temperature Ramp Hold and Bubbled To Mix, SRT-AMC-99-0180, August 30,1999.

60. T. M. Jones and D. C. Witt, CIM5 Phase III -Run \#55 - 55 wt\% Ln 25SrABS (1.87X Cerium/No Erbium) From CP-765 With Auto Standard Power and Bubbled To Mix, SRT-AMC-99-0182, September 1,1999.

61. T. M. Jones and D. C. Witt, CIM5 Run Plan SRT-AMC-99-186 to Recover From Drain Tube Pluggage, SRT-AMC-99-0186, September 2,1999.

62. T. M. Jones and D. C. Witt, CIM5 Phase III -Run'\#56 - 49 wt\% Ln 25SrABS (1.87X Cerium/No Erbium) From CP-766 With Late Cullet Addition, Modified Automatic Power Application, and Bubbled To Mix, SRT-AMC-99-0185, September 2,1999.

63. T. M. Jones and D. C. Witt, CIM5 Phase III -Run \#57 - 49 wt\% Ln 25SrABS (1.87X Cerium/No Erbium) From CP-767 With Late Marbles Addition, Modified Automatic Power Application, and Bubbled To Mix, RT-AMC-990189, September 9,1999.

64. T. M. Jones and D. C. Witt, CIM5 Phase III -Run \#58-49 wt\% Ln 25SrABS (1.87X Cerium/No Erbium) From CP-768 With Late Marbles Addition, Modified Automatic Power Application, and Bubbled To Mix, SRT-AMC-990190, September 13,1999.

65. T. M. Jónes and D. C. Witt, CIM5 Phase III -Run \#59 - 49 wt\% $\operatorname{Ln} 25$ SrABS (1.87X Cerium/No Erbium) From CP-769 With Late Marbles Addition, Modified Automatic Power Application, and Bubbled To Mix with Planned Interlock, SRT-AMC-99-0191, September 15,1999.

66. T. M. Jones and D. C. Witt, CIM5 Phase III -Run \#60 - 49 wt\% Ln 25SrABS From CP2-9 With Automated Standard Power Application, Bubbled To Mix and Planned Interlock, SRT-AMC-99-0192, September 16,1999. 
WSRC-TR-99-0434

Page 47 of 59

\section{ATTACHMENT 1}

\section{CIM5 Phase III Process Development Highlights}

Run \# 15

- 58wt\% lanthanide loading $25 \mathrm{SrABS}$

- $1.5 \mathrm{X}$ standard cerium (replacing equivalent neodymium)

- Automatic power control

- No bed'volume expansion

- 1.25" granular glass remained in vessel following pour completion

- Last three pour samples exhibited marbled appearance

Run \#16

- 58wt\% lanthanide loading $25 \mathrm{SrABS}$

- 2X standard cerium (replacing equivalent neodymium)

- Automatic power control

- Bed volume expansion at $1400^{\circ} \mathrm{C}$ during recovery from unplanned power interlock

- Bed expansion rose to within 2-3 inches of vessel top

- Bed expansion absorbed into glass pool within 20 minutes

- Residual glass monolith left after pour was dark colored suggesting heavily loaded

- All pour samples exhibited marbled appearance

\section{Run \#17}

- 58wt\% lanthanide loading 25SrABS

- Standard oxalate precipitate surrogate

- Automatic power control

- Entire pour stream collected (18 samples) to establish a lanthanide concentration profile

\section{Run \#18}

- 58wt\% lanthanide loading $25 \mathrm{SrABS}$

- Repeat of Run \#17

- Standard oxalate precipitate surrogate

- Automatic power control

- Entire pour stream collected (18 samples) to establish a lanthanide concentration profile

- Sample results similar to Run \#17

\section{Run \#19}

- 58wt\% lanthanide loading 25SrABS

- Repeat of Run \#16, except without interlock

- 2X standard cerium (replacing equivalent neodymium)

- Automatic power control

- Bed volume expansion as temperature approached $1450^{\circ} \mathrm{C}$ 
WSRC-TR-99-0434

Page 48 of 59

- Bed expansion rose to within 2-3 inches of vessel top as in Run \#16

- Bed expansion absorbed into glass pool within 20 minutes

- Additional soak time following expansion was 30 minutes less than Run \#16

- Residual glass left after pour was granular and lightly loaded

- All pour samples exhibited highly marbled, inhomogeneous appearance

\section{Run \#20}

- 58wt\% lanthanide loading $25 \mathrm{SrABS}$

- 1.7X standard cerium (replacing equivalent erbium)

- Automatic power control

- Bed volume expansion as melt approached $1450^{\circ} \mathrm{C}$ prior to soak

- Bed expansion rose to within several inches of vessel top .

- Bed expansion absorbed into glass pool within 30 minutes

- Residual glass was granular and lightly colored suggesting slight loading

- All pour samples exhibited highly marbled, inhomogeneous appearance

Run \#21

- 58wt\% lanthanide loading $25 \mathrm{SrABS}$

- $1.87 \mathrm{X}$ cerium (replacing equivalent erbium)

- Automatic power control

- Unable to establish glass pour due to obstruction within drain tube

- X-rayed drain tube to determine extent of pluggage -3/4" in tip end, and 2-1/4" plug at top of tube

- X-rayed drain tube to determine extent of pluggage - 3/4" in tip end, and 2-1/4" glass in top end

- Heated drain tube quickly to attempt to crack the plug by thermal expansion differences

- Used 16 diamond coated grinding burrs and 3 carbide drill bits to remove the $3 / 4$ " tip plug

- Re-melted vessel contents, poured glass, melted additional 50SrABS cullet to flush drain tube

Run \#22

- 58wt\% lanthanide loading 25SrABS

- Standard oxalate precipitate surrogate

- 1/4" diameter marbles of $25 \mathrm{SrABS}$ used in place of cullet

- Automatic power control

- Control system communication power interlock occurred 15 minutes into soak

- Again unable to establish glass pour due to obstruction within drain tube

- Used diamond coated grinding burrs and carbide drill bits to remove $1 / 8$ " obstruction

\section{Run \#23}

- 58wt\% lanthanide loading $25 \mathrm{SrABS}$

- Standard oxalate precipitate surrogate

- 30SrABS glass heel was in drain tube to better simulate residual glass left after a pour 
- Automatic power control

- Run processed satisfactorily with no pouring problems

\section{Rún \#24}

- 58wt\% lanthanide loading $25 \mathrm{SrABS}$

- Standard oxalate precipitate surrogate

- 30SrABS glass heel was in drain tube to better simulate residual glass left after a pour

- Automatic power control

- Run processed satisfactorily with no pouring problems

\section{Run \#25}

- Was not performed

\section{Runs \#26 and \#27}

- 50wt\% lanthanide loading $25 \mathrm{SrABS}$

- Standard oxalate precipitate surrogate

- Automatic power control - vessel coil maintained at $5.02 \mathrm{Kw}$ for duration of soak

- Run processed satisfactorily with no bed expansion or pouring problems

- Pour rate $70 \mathrm{~kg} / \mathrm{hr}$ initially, gradually decreasing with decrease in head and loading at end of pour

- No visual evidence of de-vitrification in any of the pour samples

\section{Run \#28}

- 47wt\% lanthanide loading $25 \mathrm{SrABS}$

- Standard oxalate precipitate surrogate

- Automatic power control - vessel coil maintained at $5.02 \mathrm{Kw}$ for duration of soak

- Run processed satisfactorily with no bed expansion or pouring problems

- Pour rate 37 - $43 \mathrm{~kg} / \mathrm{hr}$ initially, gradually slowing with decrease in head and loading

- No visual evidence of de-vitrification in any of the pour samples .

\section{Run \#29}

$-47 \mathrm{wt} \%$ lanthanide loading $25 \mathrm{SrABS}$

- Standard oxalate precipitate surrogate

- Automatic power control - vessel coil maintained at $5.02 \mathrm{Kw}$ for duration of soak

- Run processed satisfactorily with no bed expansion or pouring problems

- Pour rate $58 \mathrm{~kg} / \mathrm{hr}$ initially, gradually slowing with decrease in head and loading

- No visual evidence of de-vitrification in any of the pour samples

\section{Run \#30}

- 52wt\% lanthanide loading 25SrABS

- Standard oxalate precipitate surrogate

- Automatic power control - vessel coil maintained at $5.02 \mathrm{Kw}$ for duration of soak

- Run processed satisfactorily with no bed expansion or pouring problems

- Pour rate $68 \mathrm{~kg} / \mathrm{hr}$ initially, gradually slowing with decrease in head and loading

- No visual evidence of de-vitrification in any of the pour samples 
- Residual glass following pour was milky colored and granular, measuring 1/2" elevation

\section{Run \#31}

- Repeat of Run \#30

- 52wt\% lanthanide loading 25SrABS

- Standard oxalate precipitate surrogate

- Automatic power control - vessel coil maintained at $5.02 \mathrm{Kw}$ for duration of soak

- Run processed satisfactorily with no bed expansion or pouring problems

- Pour rate $68 \mathrm{~kg} / \mathrm{hr}$ initially, mirroring that of Run \#30

- No visual evidence of de-vitrification in any of the pour samples

- Residual glass following pour was milky colored and granular, measuring $1 / 2 "$ elevation

\section{Run \#32}

- 55wt\% lanthanide loading $25 \mathrm{SrABS}$

- Standard oxalate precipitate surrogate

- Automatic power control - vessel coil maintained at $5.02 \mathrm{Kw}$ for duration of soak

- Run processed satisfactorily with no bed expansion or pouring problems

- Pour rate $67 \mathrm{~kg} / \mathrm{hr}$ initially; quickly slowing with decrease in head and loading

- No visual evidence of de-vitrification in any of the pour samples

- Residual glass following pour was milky colored and granular, measuring 1" elevation

\section{Run \#33}

- Repeat of Run \#32

- 55wt\% lanthanide loading 25SrABS

- Standard oxalate precipitate surrogate

- Automatic power control - vessel coil maintained at $5.02 \mathrm{Kw}$ for duration of soak

- Run processed satisfactorily with no bed expansion or pouring problems

- Pour rate $61 \mathrm{~kg} / \mathrm{hr}$ initially, quickly slowing with decrease in head and loading

- No visual evidence of de-vitrification in any of the pour samples

- Residual glass following pour was milky colored and granular, measuring 1-1/8" elevation

\section{Run \#34}

- 50wt\% lanthanide loading $25 \mathrm{SrABS}$

- Standard oxalate precipitate surrogate

- Automatic power control - vessel coil maintained at $5.02 \mathrm{Kw}$ for duration of soak

- Run processed satisfactorily with no bed expansion or pouring problems

- Pour rate $61 \mathrm{Kg} / \mathrm{Hr}$ initially, quickly slowing with decrease in head and loading

- No visual evidence of de-vitrification in any of the pour samples

- 1/4" lightly loaded residual glass monolith with large bubbles left after pour 
WSRC-TR-99-0434

Page 51 of 59

\section{Run \#35}

- 50wt\% lanthanide loading 25SrABS

- Standard oxalate precipitate surrogate

- Automatic power control - vessel coil maintained at $5.02 \mathrm{Kw}$ for duration of soak

- Run processed satisfactorily with no bed expansion or pouring problems

- Pour rate $66 \mathrm{Kg} / \mathrm{Hr}$ initially, quickly slowing with decrease in head and loading

- No visual evidence of de-vitrification in any of the pour.samples

- 1/4" slightly higher loaded residual glass monolith with larger bubbles than Run \#34

Run \#36 .

- 49wt\% lanthanide loading 25SrABS (Selected as preferred base glass)

- Standard oxalate precipitate surrogate

- Automatic power control - vessel.coil maintained at $5.02 \mathrm{Kw}$ except during interlock

- Planned 5 minute interlock at start of peak power soak period

- Melter temp decreased from $1425^{\circ} \mathrm{C}$ to $1125^{\circ} \mathrm{C}$ during power interlock

- Temperature recovered satisfactorily with no bed expansion or pouring problems

- Pour rate $50 \mathrm{Kg} / \mathrm{Hr}$ initially, quickly slowing with decrease in head and loading

- No visual evidence of de-vitrification in any of the pour samples

- 3/8" lightly loaded residual glass monolith with bubbles .

Run \#37

- 49wt\% lanthanide loading 25SrABS (Selected as preferred base glass)

- Standard oxalate precipitate surrogate

- Automatic power control - vessel coil maintained at $5.02 \mathrm{Kw}$ except during interlock

- 16 minute interlock at start of peak power soak period

- Melter temp decreased from $1420^{\circ} \mathrm{C}$ to $984^{\circ} \mathrm{C}$ during power interlock

- Temperature recovered satisfactorily with no bed expansion or pouring problems

- Pour rate $67 \mathrm{Kg} / \mathrm{Hr}$ initially, quickly slowing with decrease in head and loading

- No visual evidence of de-vitrification in any of the pour samples

- <3/8" lightly loaded residual glass monolith without bubbles

Run \#38

- 49wt\% lanthanide loading 25SrABS (Selected as preferred base glass)

- 1/4" glass beads used instead of cullet

- Standard oxalate precipitate surrogate

- Automatic power control - vessel coil maintained at $5.02 \mathrm{KW}$ during soak

- A slight bed expansion during the vitrification phase was observed

- Pour rate $74 \mathrm{Kg} / \mathrm{Hr}$ initially, quickly slowing with decrease in head and loading

- No visual evidence of de-vitrification in any of the pour samples

- <3/8" lightly loaded residual glass monolith without bubbles

\section{Run \#39}

- 49wt\% lanthanide loading $25 \mathrm{SrABS}$ (Selected as preferred base glass)

$-1 / 4$ " glass beads used instead of cullet

- Standard oxalate precipitate surrogate 
WSRC-TR-99-0434

Page 52 of 59

- Automatic power control - vessel coil maintained at $5.02 \mathrm{KW}$ during soak

- A slight bed expansion during the vitrification phase was observed

- Pour rate $77 \mathrm{Kg} / \mathrm{Hr}$ initially, quickly slowing with decrease in head and loading

- No visual evidence of de-vitrification in any of the pour samples

- $<3 / 8$ " lightly loaded residual glass monolith without bubbles

CIM 30-1 Run

- Batch chemicals ( 1000 grams) used to produce $30 \mathrm{SrABS}$ cullet

- Material held at $1500^{\circ} \mathrm{C}$ for 2 hours prior to pour initiation

- Boric acid decomposition led to significant entrainment in off-gas stream

- Poured glass was not homogeneous: $27 \% \mathrm{SiO}_{2}$ at pour start vs. $77 \% \mathrm{SiO}_{2}$ at end of pour

- $\mathrm{Al}_{2} \mathrm{O}_{3}, \mathrm{La}_{2} \mathrm{O}_{3}$, and $\mathrm{SrO}$ content decreased $4 \mathrm{X}$ from pour start to end of pour

- Poured 895 grams of glass of 1000 grams batched to vessel

CIM 30-2 Run

- Batch chemicals (1800 grams) used to produce $30 \mathrm{SrABS}$ cullet

- Material held at $1500^{\circ} \mathrm{C}$ for 2 hours prior to pour initiation

- Boric acid decomposition led to significant entrainment in off-gas stream

- Poured glass was not homogeneoús

- Poured 1200 grams of glass of 1800 grams batched to vessel

\section{CIM Run To Mix}

- Cullet (3715 grams) from 30-1, 30-2, and 30-4 (DTTS) runs added to produce $30 \mathrm{SrABS}$ cullet

- Material held at $1500^{\circ} \mathrm{C}$ for 2 hours with argon bubbling at prior to pour initiation

- Argon flow initially at $0.25 \mathrm{SCFH}$, then increased to $0.4,0.5$, and $1.0 \mathrm{SCFH}$

- Poured glass appeared more homogeneous

- Poured 3278 grams of glass of 3715 grams batched to vessel

\section{CIM Run To Produce-35SiABS Cullet}

- Batch chemicals (2700 grams) used to produce 35 SrABS cullet

- Covered vessel with filter screen to reduce entrainment entering off-gas system

- Glass pool mixed 1-Hr 40 -Min. when $1500^{\circ} \mathrm{C}$ soak temperature was attained

- Material held at $1500^{\circ} \mathrm{C}$ for additional 20-Min. prior to pour initiation

- Poured 2445 grams of glass of 2700 grams batched to vessel

CIM $2^{\text {nd }}$ Run To Produce 35 SrABS Cullet

- Batch chemicals (2945 grams) used to produce 35StABS cullet

- Covered vessel with filter screen to reduce entrainment entering off-gas system

- Glass pool mixed 1- $\mathrm{Hr} 40-\mathrm{Min}$. when $1500^{\circ} \mathrm{C}$ soak temperature was attained

- Material held at $1500^{\circ} \mathrm{C}$ for additional 20-Min. prior to pour initiation

- Poured 2760 grams of glass of 2945 grams batched to vessel 
WSRC-TR-99-0434

Page 53 of 59

Run \#40

- 49wt\% lanthanide loading 30SrABS

- Standard oxalate precipitate surrogate

- Automatic power control - vessel coil maintained at $5.02 \mathrm{KW}$ during soak

- A slight bed expansion during the vitrification phase was observed

- Pour rate $58 \mathrm{Kg} / \mathrm{Hr}$ initially, quickly slowing with decrease in head and loading

- No visual evidence of de-vitrification in any of the pour samples

- Homogeneity of poured glass better than $25 \mathrm{SrABS}$, but still needs improvement

- 2058 grams of 30SrABS glass poured of 2190 grams targeted

\section{Run \#41}

- 49wt\% lanthanide loading 30SrABS

- Standard oxalate precipitate surrogate

- Automatic power control - vessel coil maintained at $5.02 \mathrm{KW}$ during soak

- A slight bed expansion during the vitrification phase was observed

- Pour rate $71 \mathrm{Kg} / \mathrm{Hr}$ initially, quickly slowing with decrease in head and loading

- No visual evidence of de-vitrification in any of the pour samples

- Homogeneity of poured glass better than $25 \mathrm{SrABS}$, but still needs improvement

- 2088 grams of $30 \mathrm{SrABS}$ glass poured of 2190 grams targeted

\section{Run \#42}

- 49wt\% lanthanide loading 35SrABS

- Standard oxalate precipitate surrogate

- Automatic power control - vessel coil maintained at $5.02 \mathrm{KW}$ during soak

- A severe bed expansion during the vitrification phase forced material out top of vessel

- Shut off power to melter for 5 minutes to mitigate bed expansion

- Reapplied power to melter with drain tube cooling removed to pour glass

- Experienced second bed expansion after pouring 1380 grams of glass

- 2645 grams of $35 \mathrm{SrABS}$ glass poured of 2751 grams targeted -

. Run \#43

- 49wt\% lanthanide loading 25SrABS

- Standard oxalate precipitate surrogate

- Automatic power control - vessel coil maintained at $5.02 \mathrm{KW}$ during soak

- A slight "controlled" bed expansion at the beginning of the soak/bubble phase was observed

- Bubbling initiated at beginning of soak phase - bubbled 60 minutes at 1.0 scfh argon flow

- Glass pool soaked additional 20 minutes after conclusion of bubbling

- Pour rate measured 26.3, 29.9, 32.2, 31.6, 31.0, 31.0, 29.6, 29.2, and $21.1 \mathrm{Kg} / \mathrm{Hr}$

- Homogeneity of poured glass much better than $25 \mathrm{SrABS}$ without bubbling

Run \#44

$-.49 \mathrm{wt} \%$ lanthanide loading $25 \mathrm{SrABS}$ 
WSRC-TR-99-0434

Page 54 of 59

- Standard oxalate precipitate surrogate

- Automatic power control - vessel coil maintained at $5.02 \mathrm{KW}$ during soak

- A slight "controlled" bed expansion at the beginning of the soak/bubble phase was observed

- Bubbling initiated at 10 minutes after beginning of soak phase - bubbled 30 minutes at $1.0 \mathrm{scfh}$ argon flow

- Glass pool soaked additional 20 minutes after cönclusion of bubbling

- Encountered drain tube HIT Temṕ Interlock - 36 additional minutes required to recover

- Pour rate measured 32.8, 29.5, 28.6, 27.4, 258.7, 27.7, 26.7, 26.3 and $19.8 \mathrm{Kg} / \mathrm{Hr}$

- Homogeneity of poured glass much better than 25SrABS without bubbling

Run \#45

- 49wt\% lanthanide loading $25 \mathrm{SrABS}$

- Standard oxalate precipitate surrogate

- Automatic power control - vessel coil maintained at $5.02 \mathrm{KW}$ during soak

- A slight "controlled" bed expansion at the beginning of the soak/bubble phase was observed

- Bubbling initiated at 15 minutes after beginning of soak phase - bubbled 15 minutes at $1.0 \mathrm{scfh}$ argon flow

- Glass pool soaked additional 15 minutes after conclusion of bubbling

- Encountered drain tube HI Temp Interlock - 36 additional minutes required to recover

- Pour rate measured 47.4, 31.4, 31.1, 29.4, 28.6, 27.9, 25.4, 22.2 and $11.1 \mathrm{Kg} / \mathrm{Hr}$

- In-homogeneity of poured glass evident in pour rates and product coloration

Run \#46

- 49wt\% lanthanide loading $25 \mathrm{SrABS}$

- Standard oxalate precipitate surrogate

- Automatic power control - vessel coil maintained at $5.02 \mathrm{~K} \cdot \mathrm{W}$ during soak

- A slight "controlled" bed expansion at the beginning of the soak/bubble phase was observed

- Bubbling initiated at 10 minutes after beginning of soak phase - bubbled 30 minutes at $1.0 \mathrm{scfh}$ argon flow

- Glass pool soaked additional 15 minutes after conclusion of bubbling

- Pour rate measured 32.5, 26:5, 26.9, 26.5, 24.7, 23.4, 25.2, 24.6, 25.0 and $21.1 \mathrm{Kg} / \mathrm{Hr}$

- Homogeneity of poured glass evident in pour rates and product coloration

Run \#47

- 49wt\% lanthanide loading $25 \mathrm{SrABS}$

- Standard oxalate precipitate surrogate

- Automatic power control - vessel coil maintained at $5.02 \mathrm{KW}$ during soak

- A slight "controlled" bed expansion at the beginning of the soak/bubble phase was observed 
- Bubbling initiated at beginning of soak phase - bubbled 45 minutes at 1.0 scfh argon flow

- Glass pool soaked additional 15 minutes after conclusion of bubbling

- Pour rate measured 32.0, 28.0, 30.4, 28.3, 27.4, 26.5, 24.8 and $21.8 \mathrm{Kg} / \mathrm{Hr}$

- Homogeneity of poured glass evident in pour rates and product coloration

\section{Run \#48}

- 49wt\% lanthanide loading $25 \mathrm{SrABS}$

ir. Standard oxalate precipitate surrogate

- Automatic power control - vessel coil maintained at $5.02 \mathrm{KW}$ during soak

- A slight "controlled" bed expansion at the beginning of the soak/bubble phase was observed

- Bubbling initiated at beginning of soak phase - bubbled 45 minutes at $1.0 \mathrm{scfh}$ argon flow

- Glass pool soaked additional 15 minutes after conclusion of bubbling

- Drain Tube HI Temp Interlock at pour initiation; tip cooling air left OFF as power was restored

- Pour rates were low (12 to $16 \mathrm{Kg} / \mathrm{Hr}$ ), as glass temperature was $100^{\circ} \mathrm{C}$ lower than normal .

- Homogeneity of poured glass evident based upon observation of product coloration

\section{Run \#49}

- 49wt\% lanthanide loading $25 \mathrm{SrABS}$

- $1.87 \mathrm{X}$ cerium (replacing erbium) precipitate surrogate

- Automatic power control - vessel coil maintained at $5.02 \mathrm{KW}$ during soak

- A severe bed expansion 7 minutes prior to the soak/bubble phase forced batch out of vessel

- Bubbling initiated at beginning of soak phase - bubbled 45 minutes at 1.0 scfh argon flow

- Glass pool soaked additional 15 minutes after conclusion of bubbling

- Pouring initiated to relieve vessel pressure from capped melter

- Drain tube plugged after 260 grams of glass/crystalline material was poured

\section{Run \#50}

- Was not performed

\section{Run \#51}

- 49wt\% lanthanide loading $25 \mathrm{SrABS}$

- $1.87 \mathrm{X}$ cerium (replacing erbium) precipitate surrogate

- Automatic power control - vessel coil maintained at $5.02 \mathrm{KW}$ during soak

- A severe bed expansion 5 minutes prior to the soak/bubble phase forced batch out of vessel

- Bubbling delayed 45 minutes while recovering from bed expansion

- Bubbling initiated at beginning of soak phase - bubbled 55 minutes at $1.0 \mathrm{scfh}$ argon flow 
- Glass pool soaked additional 10 minutes after conclusion of bubbling

- Decreasing pour rate indicated product was not homogeneous

\section{Run \#52}

- 58wt\% lanthanide loading $25 \mathrm{SrABS}$

- $1.87 \mathrm{X}$ cerium (replacing etbium) precipitáte súrrogate

- Automatic power control - vessel coil maintained at $5.02 \mathrm{KW}$ during soak

- A moderate bed expansion 5 minutes prior to the soak/bubble phase was confined to vessel

- Bubbling initiated at beginning of soak phase - bubbléd 60 minutes at 1.0 scfh argon flow

- Glass pool soaked additional 10 minutes after conclusion of bubbling

- Glass dripped from drain tube for 4 minutes before a steady stream was achieved

- Pour rate was $45-50 \mathrm{Kg} / \mathrm{Hr}$, but initial behavior indicated product was not homogeneous

\section{Run \#53}

- 49wt\% lanthanide loading $25 \mathrm{SrABS}$

- $1.87 \mathrm{X}$ cerium (replacing erbium) precipitate surrògate

- Automatic power control - vessel coil maintained at $5.02 \mathrm{KW}$ during soak

- Bubbling initiated prior to soak phase - bubbled at $1.5 \mathrm{scfh}$ argon flow through oxide bed

- A moderate bed expansion 5 minutes prior to the soak/bubble phase, rising to 2" below cover

- Bed expansion eventually lifted cover board at 4 minutes into the 60 minute bubbling period

- Glass pool soaked additional 10 minutes after conclusion of bubbling

- Glass steady stream was achieved immediately upon pour initiation

- Pour rate was $26-28 \mathrm{Kg} / \mathrm{Hr}$, but initial behavior indicated product was not homogeneous

Run \#54

- 49wt\% lanthanide loading $25 \mathrm{SrABS}$

- $1.87 \mathrm{X}$ cerium (replacing erbium) precipitate surrogate

- Automatic power control program paused when bed temperature reached $1180^{\circ} \mathrm{C}$ to allow oxygen produced by the cerium reduction to vent through powder oxide bed

- Attempted to hold bed centerline temperature at $1180-1200^{\circ} \mathrm{C}$ for 90 minutes

- Thermal inertia caused bed temperature to rise to $1350-1450^{\circ} \mathrm{C}$ over time

- A moderate bed expansion 54 minutes into the power hold lifted cover

- Glass pool was bubbled for 60 minutes, then soaked additional 10 minutes after bubbling

- Glass steady stream was achieved immediately upon pour initiation

- Pour rate was $21-23.7 \mathrm{Kg} / \mathrm{Hr}$, indicating product was somewhat homogeneous 
WSRC-TR-99-0434

Page 57 of 59

\section{Run \#55}

- 55wt\% lanthanide loading 25SrABS

- $1.87 \mathrm{X}$ cerium (replacing erbium) precipitate surrogate

- Automatic power control - vessel coil maintained at $5.02 \mathrm{KW}$ during soak

- A moderate bed expansion at initiation of the soak/bubble period rose to within 3" of cover

- 17 minutes into the soak period, a second bed expansion contacted the,top cover

- After the glass pool had soaked for 60 minutes at peak power, the pool was bubbled for 60 minutes, then soaked additional 10 minutes after bubbling

- Glass pouring only partly emptied the vessel before the stream stopped ( $2 \mathrm{~min} .40$ seconds pouring)

- Pour rate was $45-34 \mathrm{Kg} / \mathrm{Hr}$, indicating product was not homogeneous

- 100 grams of $49 \mathrm{SrABS}$ (cerium free) cullet was added to the vessel to flush the drain tube, followed by an additional 100 grams of 49 SrABS cullet

- Pour re-initiation was not achieved; tip of drain tube was plugged

\section{Run \#56}

- 58wt\% lanthanide loading initial charge of 25SrABS cullet

- $1.87 \mathrm{X}$ cerium (replacing erbium) precipitate surrogate.

- Automatic power control - vessel coil maintained at $5.02 \mathrm{KW}$ during soak

- Bubbling initiated at beginning of soak phase - at 1.5 scfh argon flow

- Additional 505 grams 25 SrABS cullet added to attain targeted $49 \mathrm{wt} \%$ La loading

- Total argon bubbling time extended to 90 minutes as melter recovered temperature

- Pour rate was, 27 - $25 \mathrm{Kg} / \mathrm{Hr}$, indicating product was homogeneous

- No appreciable bed expansion was evident

\section{Run \#57}

- 58wt\% lanthanide loading initial charge of 25SrABS cullet

- $1.87 \mathrm{X}$ cerium (replacing erbium) precipitate surrogate

- Automatic power control - vessel coil maintained at $5.02 \mathrm{KW}$ during soak

- Bubbling initiated at beginning of soak phase - at $1.5 \mathrm{scfh}$ argon flow

- 250 grams $25 \mathrm{SrABS}$ marbles (3/8") were added towards attaining targeted $49 \mathrm{wt} \% \mathrm{La}$ loading

- 43 minutes later, 255 grams $25 \mathrm{SrABS}$ marbles were added to yield $49 \mathrm{wt} \%$ La loaded glass

- Additional 60 minutes of argon bubbling time after final marbles addition

- Pour rate was $38-31 \mathrm{Kg} / \mathrm{Hr}$, indicating product homogeneity was marginal

- 30 gram 49SrABS addition was made after the pour sequence to provide seal plug over drain tube

Run \#58

- Duplication of Run \#57, except additional power input earlier into vitrification phase

- Measured pour rates of $38-31 \mathrm{Kg} / \mathrm{Hr}$ obtained

- 30 gram 49SrABS addition was made after the pour sequence to provide seal plug over drain tube 
WSRC-TR-99-0434

Page 58 of 59

Run \#59

- 58wt\% lanthanide loading initial charge of 25SrABS cullet

- $1.87 \mathrm{X}$ cerium (replacing erbium) precipitate surrogate

- Automatic power control - vessel coil maintained at $5.02 \mathrm{KW}$ during soak

- Bubbling initiated at beginning of soak phase - at $1.5 \mathrm{scfh}$ argon flow

- 250 grams 25 SrABS marbles (3/8") were added towards attaining targeted $49 \mathrm{wt} \%$ La loading

- After the second marble addition, the system was interlocked by pressing the E-Stop button

- When the control thermocouple reached $1250^{\circ} \mathrm{C}$, power was re-established at preinterlock settings

- Pour rate was 33 - $28 \mathrm{Kg} / \mathrm{Hr}$, indicating product homogeneity was acceptable

- 30 gram 49SrABS addition was made after the pour sequence to provide seal plug over drain tube

\section{Run \#60}

- 49wt\% lanthanide loading 25SrABंS

- Standard oxalate precipitate surrogate

- Automatic power control - vessel coil maintained at $5.02 \mathrm{KW}$ during soak

- Bubbling initiated at beginning of soak phase - at $1.5 \mathrm{scfh}$ argon flow

- While in the soak/bubbling stage, the system was interlocked by pressing the E-Stop button

- When the control thermocouple cooled to $1250^{\circ} \mathrm{C}$, power was re-applied to system

- Pour rate was 33 - $25 \mathrm{Kg} / \mathrm{Hr}$, indicating product homogeneity was acceptable

- 30 gram 49SrABS addition was made after the pour sequence to provide seal plug over drain tube 
WSRC-TR-99-0434

Page 59 of 59

\section{ATTACHMENT 2}

\section{CIM5 THERMOCOUPLE LOCATIONS}

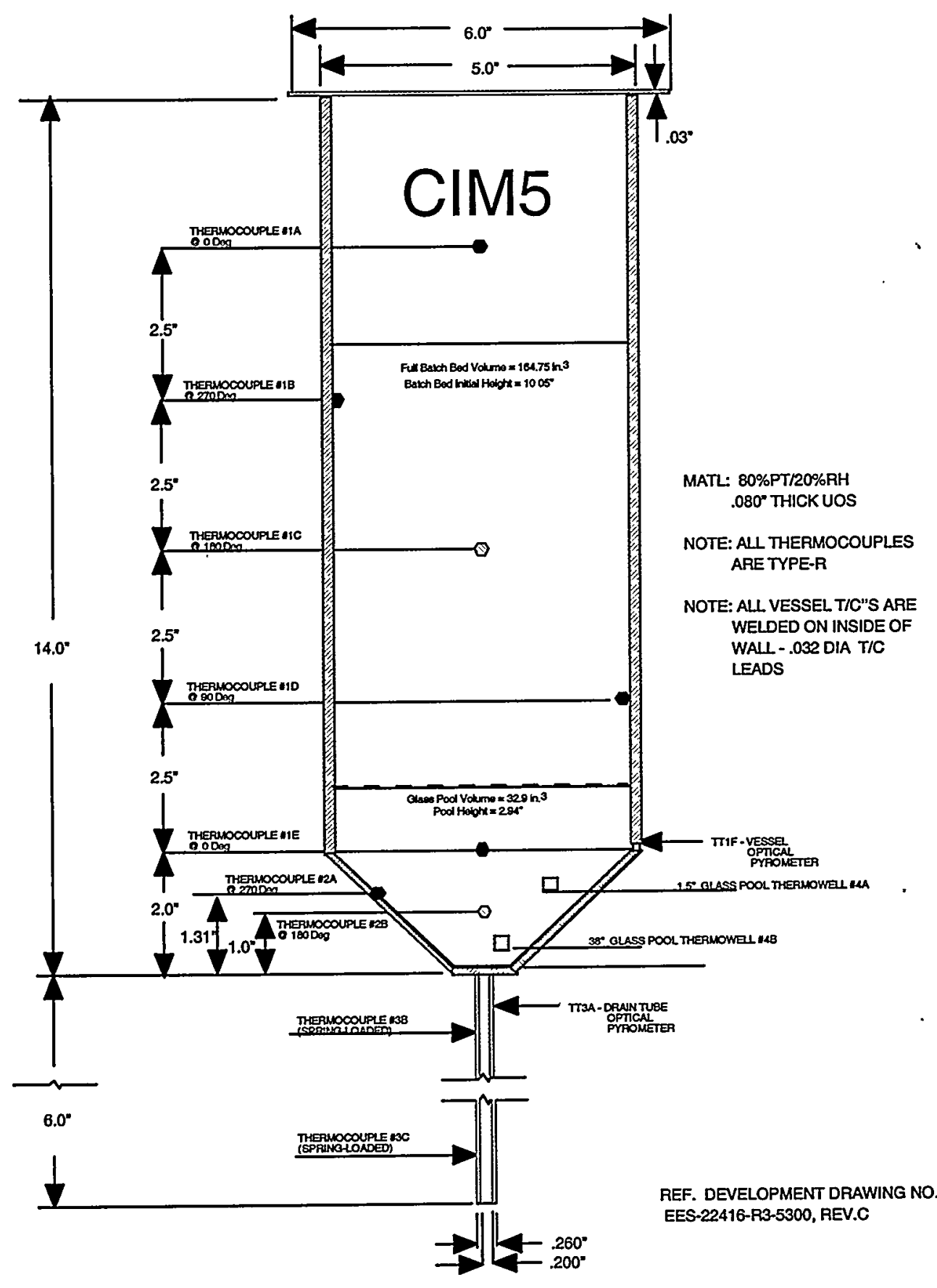




\section{DISTRIBUTION:}

L. M. Papouchado, 773-A

E. W. Holtzscheiter, 773-A

L. F. Landon, 704-1T

M. A. Baich, 704-1T

D. C. Witt, 704-1T

T. M. Jones, 704-1T

D. H. Miller, 704-1T

M. E. Stone, 704-1T

T. K. Snyder, 704-T

D. K. Peeler, 773-43A

C. B. Miller, 773-A

Am/Cm File, 704-1T

STI, 703-43A (4) 